\title{
A Review of the Measures Designed to Assess DSM-5 Personality Disorders
}

\author{
Adrian Furnham1, Rebecca Milner1, Reece Akhtar1, Filip De Fruyt ${ }^{2}$ \\ ${ }^{1}$ Research Department of Clinical, Educational and Health Psychology, University College London, London, UK \\ ${ }^{2}$ Department of Developmental, Personality and Social Psychology, Ghent University, Ghent, Belgium \\ Email: a.furnham@ucl.ac.uk
}

Received 3 July 2014; revised 1 August 2014; accepted 24 August 2014

Copyright (C) 2014 by authors and Scientific Research Publishing Inc.

This work is licensed under the Creative Commons Attribution International License (CC BY). http://creativecommons.org/licenses/by/4.0/

\begin{abstract}
The definition, classification and assessment of personality disorders (PDs) have attracted considerable debate for nearly 50 years. This paper attempts a comprehensive review of the instruments to assess all, or specific, individual disorders as described in DSM-5, including structured interviews and inventories. The review should be helpful for clinicians, researchers and also industrial and organizational psychologists, to screen and assess the personality pathology spectrum from subclinical manifestations to full blown personality pathology. A decision tree helpful to choose among the different measures is also provided.
\end{abstract}

\section{Keywords}

Personality Disorders, Personality Pathology, Measures, Questionnaires, Structured Interviews

\section{Introduction}

There has been much debate about personality disorders (PDs) over the years, particularly their definition, conceptualization, occurrence and assessment. Perhaps the greatest "shake up" in the way PDs were discussed has occurred in the move from DSM-IV (American Psychiatric Association, 2000) to DSM-5, proposing dimensional alternatives for the DSM-IV categorical diagnoses (Widiger, Livesley, \& Clark, 2009). Notwithstanding this lively debate, DSM-5 preserved in its Section 2 the categorical PDs like distinguished in DSM-IV, whilst an alternative trait system is referred to Section 3 for further evaluation and research (American Psychiatric Association, 2013). Although, there is a great deal of activity developing and validating new instruments like the Personality Inventory for DSM-5 (PID-5; Krueger, Derringer, Markon, Watson, \& Skodol, 2012) to assess and evaluate (Bagby, 2013) this new trait model, the diagnosis and assessment of categorical PDs is primarily advocated in the official nomenclature of the American Psychiatric Association. 
At the same time, the attention to PDs, both from an academic and societal perspective, expanded dramatically due to the impairing character of the diagnoses and the increasingly high financial costs involved in the treatment of patients with personality pathology (Gustavsson et al., 2012). Apart from attention from clinical psychologists to full-blown personality pathology, selection and human resources psychologists have become interested in subclinical manifestations of aberrant personality and the impact on individuals' workplace functioning. This is because a substantial proportion of the general population and workforce has personality problems themselves or has to deal with (subclinically) disordered persons as colleagues or supervisors (Wille, De Fruyt, \& De Clercq, 2013; De Fruyt, Wille, \& Furnham, 2013b). Whereas clinical psychologists have been treating patients with one or more PDs and co-occurring pathology, industrial and organisational psychologists run career development programs to coach people on how to deal with the dark sides of their personality, a common need for all these professional groups is well-designed and psychometric sound assessment instruments. In addition, they also need criteria to choose among the different instruments currently available.

The present paper provides a broad review of current PD measures together with a decision tree to choose among them. Length constraints meant we could not consider proposed personality disorders like Depressive Personality Disorder. The aim is to be comprehensive and descriptive rather than (psychometrically or conceptually) critical which would involve a different paper. We have attempted to catalogue all measures, which has not been done before. The measures are in no way psychometrically equivalent though each paper has been peer reviewed.

Over the years a large number of measures have been devised for research and practice. The aim of this review is to alert psychologists and researchers to the range of instruments available to assess the categorically conceived PDs listed in DSM-5 and provide a set of criteria by which professionals may choose one over another. In the introduction of this paper we refer to DSM-5 PDs, though it should be clear that almost all measures were developed before the release of DSM-5, so we refer to these previous DSM-editions when describing these measures. The available PD measures differ on at least four major characteristics.

First, some instruments attempt to be comprehensive and measure all of the PDs currently (or previously) thought to exist, because the nature and number of PDs have shifted across the different DSM editions. Some "admit" disorders that others discount, but the usual number is around 10 - 15 disorders. On the other hand, some instruments set out simply to measure one very specific disorder. Second, there seem to be four most common methods to assess the PDs: structured diagnostic interviews, rating instruments for clinicians, self-report questionnaires and other-report questionnaires (Friedman, Oltmanns, \& Turkheimer, 2007). Thus, two use observer data (clinician, family) and two use self-report data approaches towards measurement. By far the most common however are questionnaires and structured interviews. Third, some measures are about subtypes of the PD in the sense that they are multidimensional measures that yield scores on different, but related facets of the disorder. For example, some measures and theorists may distinguish between grandiose and vulnerable, or communal and agentic Narcisistic PD (NPD; Gebauer, Sedikides, Verplanken, \& Maio, 2012). Most measures, however, mimic DSM-5 categorical criteria and are not about the distinction among subtypes of a specific PD.

Fourth and finally, PD measures have been developed for essentially five target groups. The first group of users are clinicians attempting a reliable and valid diagnosis of a PD. The second is a related group, namely academic researchers who may be testing theories of the aetiology or prognosis of a PD eventually after treatment. Industrial and organisational psychologists form a third professional group interested in evaluating aberrant personality and subclinical forms of personality pathology in the context of personnel selection or career coaching and development. Finally, there are two other groups, namely "lay people" who may be interested in self-diagnosis, but also relatives of those with a specific PD requiring information about personality disorder symptoms and its prognosis.

There are, inevitably, a number of instruments on the web with unknown psychometric properties as well as various "popular books" that attempt to explain and describe the PDs for the lay public. The present review, however, primarily attempts a comprehensive overview for the first three groups interested in the professional assessment of personality pathology.

Before listing and discussing the different measures, we provide an overview of the DSM-5 PDs with their clinical labels and a short description in Table 1. This table further shows the labels and descriptions of PDs as they are used in a popular measure frequently used in occupational and career coaching and development settings (Hogan \& Hogan, 1997; Furnham, Trickey, \& Hyde, 2012). The remaining columns illustrate the labels used in books written by psychiatrists (Oldham \& Morris, 1991), clinical psychologists (Miller, 2008) and I/O 
Table 1. Different labels for traits associated with similar disorders.

\begin{tabular}{|c|c|c|c|c|c|c|}
\hline \multicolumn{2}{|r|}{ DSM-IV Personality Disorder } & \multicolumn{2}{|c|}{$\begin{array}{c}\text { Hogan \& Hogan (1997) } \\
\text { HDS Themes }\end{array}$} & \multirow{2}{*}{$\begin{array}{c}\text { Oldham \& } \\
\text { Morris (1991) } \\
\text { Vigilant }\end{array}$} & \multirow{2}{*}{$\begin{array}{r}\text { Miller } \\
(2008) \\
\text { Vigilantes }\end{array}$} & \multirow{2}{*}{$\begin{array}{c}\text { Dotlich \& } \\
\text { Cairo (2003) } \\
\text { S Habitual }\end{array}$} \\
\hline Paranoid & $\begin{array}{l}\text { Distrustful and suspicious of } \\
\text { others; motives are interpreted } \\
\text { as malevolent. }\end{array}$ & Sceptical & $\begin{array}{l}\text { Cynical, distrustful and } \\
\text { doubting others' true } \\
\text { intensions. }\end{array}$ & & & \\
\hline Schizoid & $\begin{array}{l}\text { Emotional coldness and detachment } \\
\text { from social relationships; indifferent } \\
\text { to praise and criticism. }\end{array}$ & Reserved & $\begin{array}{l}\text { Aloof, detached and } \\
\text { uncommunicative; lacking } \\
\text { interest in or awareness of } \\
\text { the feelings of others. }\end{array}$ & Solitary & Oddballs & Aloof \\
\hline Schizotypal & $\begin{array}{l}\text { Odd beliefs or magical thinking; } \\
\text { behaviour or speech that is odd, } \\
\text { eccentric or peculiar. }\end{array}$ & Imaginative & $\begin{array}{l}\text { Acting and thinking in } \\
\text { creative and sometimes } \\
\text { odd or unusual ways. }\end{array}$ & Idiosyncratic & $\begin{array}{l}\text { Creativity } \\
\text { and vision }\end{array}$ & Eccentric \\
\hline Antisocial & $\begin{array}{l}\text { Disregard for the truth; impulsivity } \\
\text { and failure to plan ahead; failure } \\
\text { to conform. }\end{array}$ & Mischievous & $\begin{array}{l}\text { Enjoying risk taking and } \\
\text { testing the limits; needing } \\
\text { excitement; manipulative, } \\
\text { deceitful, cunning and } \\
\text { exploitative. }\end{array}$ & Adventurous & Predators & Mischievous \\
\hline Borderline & $\begin{array}{l}\text { Inappropriate anger; unstable and } \\
\text { intense relationships alternating } \\
\text { between idealisation and devaluation. }\end{array}$ & Excitable & $\begin{array}{l}\text { Moody and hard to } \\
\text { please; intense but short-lived } \\
\text { enthusiasm for people, } \\
\text { projects or things. }\end{array}$ & Mercurial & Reactors & Volatility \\
\hline Histrionic & $\begin{array}{l}\text { Excessive emotionality and attention } \\
\text { seeking; self dramatising, theatrical } \\
\text { and exaggerated emotional expression. }\end{array}$ & Colourful & $\begin{array}{l}\text { Expressive, animated and } \\
\text { dramatic; wanting to be } \\
\text { noticed and needing to be } \\
\text { the centre of attention. }\end{array}$ & Dramatic & Emoters & Melodramtic \\
\hline Narcissistic & $\begin{array}{l}\text { Arrogant and haughty behaviours } \\
\text { or attitudes, grandiose sense of } \\
\text { self-importance and entitlement. }\end{array}$ & Bold & $\begin{array}{l}\text { Unusually self-confident; } \\
\text { feelings of grandiosity and } \\
\text { entitlement; over valuation } \\
\text { of one’s capabilities. }\end{array}$ & Self-Confidence & Preeners & Arrogance \\
\hline Avoidant & $\begin{array}{l}\text { Social inhibition; feelings of } \\
\text { inadequacy and hypersensitivity } \\
\text { to criticism or rejection. }\end{array}$ & Cautious & $\begin{array}{l}\text { Reluctant to take risks for } \\
\text { fear of being rejected or } \\
\text { negatively evaluation. }\end{array}$ & Sensitive & Shrinkers & $\begin{array}{l}\text { Excessive } \\
\text { Caution }\end{array}$ \\
\hline Dependent & $\begin{array}{l}\text { Difficulty making everyday } \\
\text { decisions without excessive advice } \\
\text { and reassurance; difficulty } \\
\text { expressing disagreement out of fear } \\
\text { of loss of support or approval. }\end{array}$ & Dutiful & $\begin{array}{l}\text { Eager to please and reliant } \\
\text { on others for support and } \\
\text { guidance; reluctant to take } \\
\text { independent action or to go } \\
\text { against popular opinion. }\end{array}$ & Devoted & Clingers & $\begin{array}{l}\text { Eager to } \\
\text { Please }\end{array}$ \\
\hline $\begin{array}{l}\text { Obsessive- } \\
\text { Compulsive }\end{array}$ & $\begin{array}{l}\text { Preoccupations with orderliness; } \\
\text { rules, perfectionism and control; } \\
\text { over- Conscientiousness and } \\
\text { inflexible. }\end{array}$ & Diligent & $\begin{array}{l}\text { Meticulous, precise and } \\
\text { perfectionistic, inflexible } \\
\text { about rules and procedures; } \\
\text { critical of others; . }\end{array}$ & Conscientious & Detailers & Perfectionistic \\
\hline $\begin{array}{l}\text { Passive- } \\
\text { Aggressive }\end{array}$ & $\begin{array}{l}\text { Passive resistance to adequate } \\
\text { social and occupational performance; } \\
\text { irritated when asked to do } \\
\text { something he/she does not want to. }\end{array}$ & Leisurely & $\begin{array}{c}\text { Independent; ignoring } \\
\text { people's requests and } \\
\text { becoming irritated or } \\
\text { argumentative if they } \\
\text { persist. }\end{array}$ & Leisurely & Spoilers & $\begin{array}{l}\text { Passive } \\
\text { Resistance }\end{array}$ \\
\hline
\end{tabular}

psychologists (Dotlich \& Cairo, 2003) to explain the PDs to lay people.

\section{Available Measures}

This paper covers the measures available, including those assessing all PDs, as well as each PD in turn. We also acknowledge the fact that there are instruments intended to measure the prevalence of specific symptoms of PDs, yet have excluded these from our analysis due to space constraints. Likewise, we have also excluded alternative dimensional conceptualisations of PDs and personality pathology (Clark, 2007), except when these methods are specifically targeted to assess the categorical DSM-5 PDs. We hence do not explicitly discuss and reiterate the discussion on alternative dimensional models of PDs (Widiger \& Clark, 2000; Widiger \& Costa, 2013), except 
when these provide direct assessments of the categorical PDs. To our knowledge a review such as this has not been done before, though there are review papers that have reviewed some instruments at the same time (Clark \& Harrison, 2001; McDermut \& Zimmerman, 2008; Segal \& Coolidge, 2007; Widiger \& Boyd, 2009; Zimmerman, 2003).

Apart from usual bibliometric investigations, we emailed over 50 experts (mainly those on the editorial board of specialist PD journals) in the area showing them our list and asking if they knew of any measures that we were not aware of. This did yield half a dozen extra, and we are reasonably satisfied that we have been able to locate most important measures.

\section{Measures of all the Personality Disorders (See Table 2)}

\subsection{Structured Interviews}

The Structured Interview for DSM-III Personality Disorders (SIDP; Pfohl, Stangl, \& Zimmerman, 1983) has largely fallen out of favour because of its focus on DSM-III PDs. Despite this, it has been shown to hold highly variable test-retest reliabilities ranging from .24 for obsessive-compulsive PD to .74 for histrionic PD, with an average level of .54 (First et al., 1995). Pfohl, Blum and Zimmerman (1997) adapted the SIDP at the advent of the DSM-IV, releasing The Structured Interview for DSM-IV Personality Disorders (SIDP-IV)—a fairly brief interview (lasting roughly 60 minutes) that features both a patient and an informant. This is beneficial as it helps gain a different perspective on the patient in question. There are two versions of the SIDP-IV: a diagnostic version and a "topical" version, though the only difference is the order of the questions. The benefit of including a topical version is that it includes natural questions that are designed to make interviewing defensive patients easier. Much like the International Personality Disorder Examination (IPDE; Loranger, 1999; see below), the SIDP-IV can also assess for Personality Disorder Not Specified (PDNOS) however the SIDP-IV will diagnose a PDNOS only when two or more disorders are one criterion short of the diagnostic threshold. Jane, Pagan, Turkheimer, Fiedler and Oltmanns (2006) found inter-rater reliability for each PD being greater than .70, a finding also supported by Damen, De Jong and Van Der Kroft (2004).

The Diagnostic Interview for DSM-IV Personality Disorders (DIPD-IV; Zanarini, Frankenburg, Sickel, \& Yong, 1996). This semi-structured clinical interview assesses all DSM-IV PDs, and like most clinical interviews, specialised training is required before the interview can be administered. The interview has 108 items, with each disorder rated on a scale of 0 (disorder is absent) to 2 (disorder is present). If the totalled scores exceed a threshold the clinician can diagnose a disorder. The original paper cites internal consistency levels ranging from .64 to .93 , with six of the disorders having levels greater than .70; acceptable levels of test-retest reliability with Kappa $=.58$ to 1 are reported over a 6-month period. These are also called dependability coefficients (Chmielewski \& Watson, 2009). The DIPD-IV was used in the Collaborative Longitudinal Personality Disorders Study (CLPS).

The Structured Clinical Interview for DSM-IV Personality Disorders (SCID-II; First, Gibbons, Spitzer, Williams, \& Benjamin, 1997) is widely used and researched, unlike the DIPD-IV. The respondent typically first completes a questionnaire and interviewers then follow up responses. It is also the shortest interview (140 items), lasting minimally 30 minutes (the DIPD-IV lasts around 90 minutes). The SCID-II measures all DSM-IV PDs and the associated symptoms in the order they are presented in the DSM-IV. Some have criticised its brevity (Rogers, 2003). Investigations into the instrument's reliability and validity have shown considerable support. Lobbestael, Leurgans and Arntz (2011) found mean kappa scores of .84. Moran et al. (2003) provided further support with mean kappa scores of .71, but others have reported lower Kappas (Hyler, Skoldol et al., 1990, 1992). Skodol et al. (1991) investigated the convergent validity of the SCID-II by comparing it to diagnoses made by the International Personality Disorder Examination (IPDE; Loranger, 1999). The authors found that the two instruments' diagnoses for each PD correlated from .58 to .87, suggesting that both instruments measure the same PDs to a "reasonable" extent.

The Personality Disorder Interview (PDI-IV; Widiger, Mangine, Crobitt, Ellis, \& Thomas, 1995) is another semi-structured interview that assesses each of the 94 personality disorder criteria displayed in the DSM-IV, making it a lengthy interview lasting around 90 - 120 minutes. Rogers (2001) supports the instrument's extensive criteria, however criticises its sometimes sophisticated and complex language. This is a particularly valid concern when using the instrument with adolescents and cognitively impaired patients. Rogers (2001) also notes how, despite high levels of reliability, its little adoption within clinical environments has proven to be an 
Table 2. A review of measures that attempt to measure all the disorders.

\begin{tabular}{|c|c|c|c|c|c|}
\hline Name of Instrument & Author & $\begin{array}{l}\text { Number of } \\
\text { Items }\end{array}$ & Dimensions & Reliability & Validity \\
\hline $\begin{array}{l}\text { Structured Interview } \\
\text { for DSM-III } \\
\text { Personality } \\
\text { Disorders (SIDP) }\end{array}$ & $\begin{array}{l}\text { Pfohl, Stangl, \& } \\
\text { Zimmerman, } 1983\end{array}$ & & $\begin{array}{l}\text { All DSM-III } \\
\text { Personality } \\
\text { Disorders }\end{array}$ & $\begin{array}{l}\text { Test-retest reliabilities range } \\
\text { between } .24-.74 \text {, with an } \\
\text { average of } .54 \text {. }\end{array}$ & \\
\hline $\begin{array}{l}\text { The Diagnostic Interview F } \\
\text { for DSM-IV Personality } \\
\text { Disorders (DIPD-IV). }\end{array}$ & $\begin{array}{l}\text { Zanarini, M. C., } \\
\text { Frankenburg, F. R., } \\
\text { Sickel, A. } \\
\text { E., \& Yong, L. } \\
\text { (1996). }\end{array}$ & 108 & $\begin{array}{l}\text { All DSM-IV } \\
\text { Personality } \\
\text { Disorders }\end{array}$ & $\begin{array}{l}\text { Internal Consistency ranges } \\
\text { between } .64 \text { to } .93 \\
\text { Test-Retest Reliability ranges } \\
\text { between } .58 \text { to } 1.00\end{array}$ & \\
\hline $\begin{array}{l}\text { The Structured Interview } \\
\text { for DSM-IV Personality } \\
\text { Disorders (SIDP-IV) }\end{array}$ & $\begin{array}{c}\text { Pfohl, Blum, \& } \\
\text { Zimmerman (1997) }\end{array}$ & & $\begin{array}{l}\text { All DSM-IV } \\
\text { Personality } \\
\text { Disorders }\end{array}$ & $\begin{array}{l}\text { Interrater reliability for each } \\
\text { of the PD criteria was } \\
\text { generally more than } 0.70 \text {. }\end{array}$ & \\
\hline
\end{tabular}

The SCID-II/PQ

was found to have moderate convergent validity with the NPD section of the SCID-II (Campbell \& Miller, 2011).

The SCID-II and the IPDE was shown to hold good convergent validity) .58 - .87;

Skodol et al., 1991).
Test-retest reliabilities between $71-.8$
Widiger, Mangine, Corbitt, Ellis, \& Thomas, 1995 International Personality
Disorder Examination (IPDE)
Loranger, 1998;

Loranger, 1999; Loranger et al., 1987
The International Personality Disorder Examination Questionnaire (IPDEQ)
The World Health Organisation

\author{
Semi-Structured \\ Interview \\ Questions for \\ assessment of each \\ of the 94 individual \\ personality disorder \\ diagnostic criteria are \\ presented. \\ The IPDE is a \\ structured clinical \\ interview that \\ systematically surveys \\ the phenomenology \\ and life experiences \\ relevant to the \\ diagnosis of all \\ DSM-IV Axis II \\ (and ICD-10) \\ personality disorders \\ 1) Work, \\ 2) Self, \\ 3) Interpersonal \\ relationships \\ 4) Affects, \\ 5) Reality testing, \\ 6) Impulse control
}

Inter-rater reliabilities range between .81 - .92 (Lenzenweger, 1999).
99 Items
The diagnosis of any PD was highly reliable with phi > .92.

However, diagnosis of non-specific PD was not reliable at all (phi close to 0 ) suggesting that this is a true residual category. Diagnoses of specific PDs were highly reliable with the exception of schizoid PD.

Diagnosis of antisocial and Borderline PDs were perfectly reliable with phi equal to 1.00 (Fountoulakis et al., 2002). 


\section{Continued}

Iowa Personality Disorder Screen (IPDS)
Langbehn, Pfohl, \& Reynolds et al. 1999.
All DSM-III-R

Personality Disorders
The average internal consistency was .72 (Langbehn et al., 1999).
Internal consistency reliability on average $=.82$. Subscale reliabilities were lower averaging .66 .
Blind administration of the IPDS yielded excellent sensitivity (92\%) and good specificity (79\%), using a subset of five screening items (Langbehn et al., 1999).
The personality assessment inventory (PAI)
Morey (1991)
Clinical:

1) Somatic Complaints

2) Anxiety

3) Anxiety-Related

Disorders

4) Depression

5) Mania

6) Paranoia

7) Schizophrenia

8) Borderline Features

9) Antisocial Features

10) Alcohol Problems

11) Drug Problems

Interpersonal Scales

1) Dominance

2) Warmth

Treatment Scales

1) Aggression

2) Suicidal Ideation

3) Stress

4) Non-support

5) Treatment Rejection Validity Scales

1) Infrequency

2) Negative

Impression

3) Positive Impression

4) Inconsistency

\section{All DSM-IV}

oran, Leese, Lee, Walters, Graham, Thornicroft, \&

Personality:

Abbreviated Scale

(SAPAS)
Mann (2003)
Personality Disorders

The Hogan Development Hogan \& Hogan, Survey

The Omnibus Personality Loranger, 1994, Inventory (OMNI)

The scales were found to significantly correlate with the prevalence of life-events in psychiatric patients, except for the mania and anxiety scales.

When compared to the SCID-II, the SAPAS was found to have a good balance of sensitivity (.73) and specificity (.9; Pluck, Sirdifield, Brooker \& Moran, 2012).

1) Excitable

2) Sceptical

3) Cautious

4) Reserved

5) Leisurely

6) Bold

7) Mischievous

8) Colourful

9) Imaginative

10) Diligent

11) Dutiful

This questionnaire uses a seven-point Likert-type scale to measure features of all DSM-IV Axis II personality disorders

The HDS can predict work success, as well as each factor being reduced to clusters $\mathrm{A}$, $B$ and $C$ of the DSM-IV (Furnham et al., 2012). 


\section{Continued}

Schedule for

Nonadaptive and Adaptive Personality (SNAP)

The Personality

Diagnostic

Questionnaire (PDQ)
Hyler et al., 1988163 items

All DSM-III

Personality

Disorders
Personality

Disorders

The Personality Diagnostic Questionnaire Revised (PDQ-R)

Hunt \& Andrews, 1992

152 items Personality Disorders

Test-retest reliabilities are greater than .76 (Uehara et al. 1997)

Test-retest reliabilities averaging .67.

Test-retest correlation coefficients over 7 to 14 months ranged from .59 to .84. (Melley, et al., 2002)

Internal consistency ranges between .43 - .70 (Hyler \& Lyons, 1988). Test-retest reliabilities are greater than 56 (Hurt et al., 1984)

The Personality Diagnostic Questionnaire 4th Edition (PDQ-4)
Hyler, 1994

99 items

Coolidge axis-II inventory (CATI)
Coolidge, $1984 \quad 225$ items

13 Personality

Disorder Scales

(DSM-II)

3 Axis I Disorders
Coolidge axis-two inventory (SCATI)
Coolidge, $2001 \quad 70$ items
All DSM-IV

Personality Disorders
Excellent test-retest reliability (.90) has been established, as well as moderate internal consistency (.76). (Coolidge \& Merwin, 1992).

Watson \& Sinha (1996) - a gender difference was found on the antisocial scale. Age differences were found for several PD scales in that younger respondents (17 - 24 years) scored higher than the older ones (25 - 57 years).

The test has demonstrated reliability and validity and has been used in a variety of contexts, such as attributes of psychology majors in college (McCray, King, \& Bailly, 2005).

Despite the scales being reduced from an average of approximately 25 items to 5 items in length, the SCATI has good internal reliability (Watson \& Sinha, 2007) Multivariate analysis revealed that the internal structure of the SCATI is similar to the original. The SCATI is found to have good internal reliability.
Our results support the predictive validity of the diagnostic scales on the SNAP

(Clark, 1993).

SNAP scores can predict cluster A and $\mathrm{C}$ diagnoses.

The PDQ-R showed high sensitivity and moderate specificity

for most axis II

disorders (Hyler et al.,1992

Compared to the SCID-II, Kappa levels were no lower than .50. The PDQ-4 demonstrated high sensitivity and low specificity.

(Abdin et al., 2011)

The test has demonstrated reliability and validity and has been used in a variety of contexts, such as attributes of psychology majors in college (McCray,

King, \& Bailly, 2005), A 50\% concordance rate with clinicians' diagnoses for 24 personality-disordered out-patients was found (Coolidge \& Merwin, 1992)

PCA and CFA reveal that the internal structure of the test has dimensions similar to the full CATI. Therefore, the SCATI is an instrument of value for further research (Watson \& Sinha, 2007) 


\section{Continued}

\begin{tabular}{|c|c|c|c|c|c|}
\hline $\begin{array}{c}\text { Millon Clinical } \\
\text { Multiaxial Inventory-III } \\
\text { (MCMI-III) }\end{array}$ & $\begin{array}{c}\text { Millon, Millon, } \\
\text { Davis \& Grossman } \\
\text { (2006) }\end{array}$ & 175 & $\begin{array}{c}14 \text { Personality } \\
\text { Disorder Scales; } 11 \\
\text { Moderate Personality } \\
\text { Disorder Scales; } \\
3 \text { Severe personality } \\
\text { Pathology Scales; } \\
10 \text { Clinical Syndrome } \\
\text { Scales; } 7 \text { Moderate } \\
\text { Syndrome Scales; } \\
3 \text { Severe Syndrome } \\
\text { Scales Corrections } \\
\text { Scales; } 3 \text { Modifying } \\
\text { Indices; } 2 \text { Random } \\
\text { Response Indicators; } \\
\text { 42 Grossman } \\
\text { Personality Facet } \\
\text { Scales }\end{array}$ & $\begin{array}{l}\text { Examining the temporal } \\
\text { stability of the personality } \\
\text { disorder subscales from the } \\
\text { MCMI: Psychiatric inpatients } \\
\text { completed the MCMI at } \\
\text { initial admission and at the } \\
\text { next admission (within } 2 \text { years). } \\
\text { The scales demonstrated } \\
\text { adequate stability. } \\
\text { High retest correlations for the } \\
\text { MCMI clinical syndrome } \\
\text { subscales-Overholser (1990). }\end{array}$ & $\begin{array}{l}\text { Retzlaff (1996) found } \\
\text { the MCMI-III’s } \\
\text { predictive power to } \\
\text { range between .00 } \\
\text { to .32, however Millon } \\
\text { et al. (1997) found } \\
\text { the diagnostic validity } \\
\text { to range } \\
\text { between .33 - .93, } \\
\text { with an average } \\
\text { coefficient of .64. }\end{array}$ \\
\hline $\begin{array}{c}\text { Personality Beliefs } \\
\text { Questionnaire (PBQ) }\end{array}$ & Beck \& Beck, 1991. & 126 & $\begin{array}{l}10 \text { Personality } \\
\text { disorders: } \\
\text { 1) Avoidant } \\
\text { 2) Dependent } \\
\text { 3) Obsessive- } \\
\text { Compulsive } \\
\text { 4) Histrionic } \\
\text { 5) Passive-Aggressive } \\
\text { 6) Narcissistic } \\
\text { 7) Paranoid } \\
\text { 8) Schizoid } \\
\text { 9) Antisocial } \\
\text { 10) Borderline }\end{array}$ & $\begin{array}{l}\text { PBQ administered to students, } \\
\text { showing good internal } \\
\text { consistency across scales; } \\
\text { Cronbach's alphas ranged } \\
\text { from .77 to .93. Test-retest } \\
\text { correlation coefficients over a } \\
\text { month interval were high, } \\
\text { ranging from .63 } \\
\text { (passive-aggressive) to .82 } \\
\text { (paranoid; Trull, et al.,1993). }\end{array}$ & $\begin{array}{l}\text { Modest correlations } \\
\text { were obtained } \\
\text { between the PBQQ } \\
\text { and measures of PDs } \\
\text { such as the PDQ-R } \\
\text { (Hyler et al., 1992), } \\
\text { and the Minnesota } \\
\text { Muliphasic Personality } \\
\text { Inventory (Morey et } \\
\text { al., 1985). These } \\
\text { results question the } \\
\text { criterion validity of } \\
\text { the PBQ for } \\
\text { nonclinical PD traits } \\
\text { (Trull, et al., 1993). }\end{array}$ \\
\hline $\begin{array}{l}\text { The PBQ-Short Form } \\
\text { (PBQ-SF) }\end{array}$ & $\begin{array}{l}\text { Butler, Beck, \& } \\
\text { Cohen, } 2007\end{array}$ & 65 & $\begin{array}{c}\text { All DSM-IV } \\
\text { Personality Disorders }\end{array}$ & $\begin{array}{l}\text { Internal consistency } \\
\text { coefficients range } \\
\text { between } .81-.92 . \\
\text { Test-retest correlations } \\
\text { range from } .57-.82 \text { (Butler } \\
\text { et al., 2007). }\end{array}$ & \\
\hline $\begin{array}{l}\text { Minnesota multiphasic } \\
\text { personality inventory } \\
\text { (MMPI) for DSM-III }\end{array}$ & $\begin{array}{l}\text { Morey, Waugh, \& } \\
\text { Blashfield (1985) }\end{array}$ & & $\begin{array}{l}\text { 1) Histrionic } \\
\text { 2) Narcissistic } \\
\text { 3) Borderline } \\
\text { 4) Antisocial } \\
\text { 5) Depressed } \\
\text { 6) Obsessive- } \\
\text { Compulsive } \\
\text { 7) Passive-Aggressive } \\
\text { 8) Paranoid } \\
\text { 9) Schizotypy } \\
\text { 10) Avoidant } \\
\text { 11) Schizoid }\end{array}$ & $\begin{array}{l}\text { The complete version of these } \\
\text { scales yielded internal } \\
\text { consistency estimates superior } \\
\text { to those obtained in examining } \\
\text { the original clinical scales from } \\
\text { the MMPI (from previous } \\
\text { versions of the DSM). Hence, } \\
\text { it appears that the derived } \\
\text { scales are reliable as defined } \\
\text { by internal consistency- } \\
\text { Morey, Waugh, \& Blashfield, } \\
1985 \text {. }\end{array}$ & $\begin{array}{l}\text { This study found that } \\
\mathbf{5} \text { of the } \mathbf{1 1} \text { MMPI-PD } \\
\text { scales correlated } \\
\text { positively and } \\
\text { significantly with the } \\
\text { corresponding } \\
\text { MCMI-PD scales, } \\
\text { which gives limited } \\
\text { support for the } \\
\text { concurrent validity } \\
\text { of the MMPI-PD } \\
\text { scales when the } \\
\text { MCMI-PD scales } \\
\text { were used as the } \\
\text { criterion measures. } \\
\text { The Schizoid, } \\
\text { Avoidant, Dependent, } \\
\text { Histrionic, and } \\
\text { Narcissistic scales } \\
\text { achieved significant } \\
\text { correlation. } \\
\text { Overall, the study } \\
\text { supports the limited } \\
\text { validity and diagnostic } \\
\text { utility of the } \\
\text { MMPI-PD scales- } \\
\text { Schuler, Snibbe, \& } \\
\text { Buckwalter, 1994. }\end{array}$ \\
\hline
\end{tabular}


obstacle when evaluating its validity. Widiger, Costa and Samuel (2006) argue that the PDI-IV's strength lies within its manual and compared the PDI-IV's manual to manuals of other semi-structured interviews. Most are lacking normative data, statistical evidence for reliability and validity, and practical guidance, issues covered in the PDI-IV's manual.

The International Personality Disorder Examination (IPDE; Loranger, 1999) is a structured interview that is able to assess PDs across both the DSM-IV and ICD-10. The IPDE scores individuals dimensionally ("negative", "probable" and "definite") (Rogers, 2001). It demonstrates excellent inter-rater reliabilities (.81 to .92; Lenzenweger, 1999). The IPDE's strengths are that it can assess PDNOS, providing that the individual has scored on at least 10 different PD criteria, and has internationally validity as it was developed alongside the WHO. It is used in the Longitudinal Study of Personality Disorders (LSPD).

The International Personality Disorder Examination Questionnaire (IPDEQ, Loranger, 1999) is a screening tool to be used alongside the IPDE. Consisting of 99 items, it assesses PDs across six scales that represent everyday functioning (work, self, interpersonal relationships, affect, reality testing and impulse control). Loranger suggests that if an individual scores highly on at least three of the scales, then the IPDE should be subsequently used. Slade, Peters, Schneiden and Andrews (2006) found the IPDEQ to accurately predict anti-social PD, and Lewin, Slade, Andrews, Carr and Hornabrook (2005) found that the IPDEQ's scores were not only psychometrically sound, but also provided a good index for the likelihood of developing a PD in an epidemiological study, therefore suggesting its use outside of clinical environments. Fountoulakis et al. (2002) compared IPDEQ scores with the PD diagnoses, and found that the onset of specific PDs had strong phi coefficients > .91, suggesting good reliability.

The Iowa Personality Disorder Screen (IPDS; Langbehn et al., 1999) is an 11 item semi-structured interview which is essentially a screening instrument measuring DSM-III PDs. The interview only lasts around five minutes. The original authors found sensitivity validities being as high as $92 \%$ and specificity validities as high as 72\% - a finding further supported by Trull and Amdur (2001) in a non-clinical population. Olssøn, Sørebø, and Dahl (2011) also found that within psychiatric outpatients, the 11 items held an average internal consistency of .70, with positive prediction power averaging at .66 and correctly classifying PDs in comparison to the SCID-II on average at 64\%. Similarly to the Personality Beliefs Questionnaire (PBQ-SF; Beck \& Beck, 1991; see further in this paper), the IPDS stands up well against other instruments due to its extreme brevity and good statistical properties.

The Shedler-Westen Assessment Procedure 200 (SWAP-200). There are various versions of this measure including the SWAP-II and SWAP-II-A (Westen \& Shedler, 2007), an adolescent version. Clinically experienced interviewers are required to sort the 200 personality descriptive items into 8 categories from most descriptive to not descriptive or irrelevant. A computer program then reports DSM-IV PD diagnoses, personality diagnoses for alternative, empirically derived personality syndromes, and dimensional trait scores. Westen and Shedler (2007) provide both reliability and validity evidence of both versions of the test.

\subsection{Questionnaires (See Table 3)}

The Personality Diagnostic Questionnaire-4 (PDQ-4, Hyler, 1994) consists of 99 items, that measure all 10 of the DSM-IV PDs. Okada and Oltmanns (2009) found acceptable test-retest validities over different three time periods, with an average of .67. Abdin et al. (2011) investigated the PDQ-4's efficacy of being used as a screening instrument for mentally ill inmates, by comparing its validity with the SCID-II. Generally there was moderate agreement between the two instruments with Kappa levels no lower than .50. They did find that the PDQ-4 held high sensitivity (the probability of the likelihood of being diagnosed with a PD across both instruments) and low specificity (the likelihood that both instruments detect an absence of PD). When looking at specific PDs, sensitivities ranged from poor (dependent PD; .30) to good (antisocial PD; .78). Abdin et al. (2011) who used a translation in Singapore concluded that the PDQ-4 is statistically robust enough to be used as a screening instrument.

There are earlier versions of the PDQ-4: the PDQ (Hyler, Rieder, Williams, Spitzer, Hendler, \& Lyons, 1988) and the PDQ-R (Hyler \& Rieder, 1987). The PDQ consists of 163 items, but it is in accordance with the DSM-III. Participants respond to items with true/false answers. The PDQ has been found to have poor levels of internal consistency (.43 to .70; Hyler \& Lyons, 1988) and test-retest reliabilities larger than .56 (Hurt, Hyler, Frances, Clarkin, \& Brent, 1984). The PDQ-R was created as a response to the changes found within the 
Table 3. A review of measures that attempt to measure specific disorders.

\begin{tabular}{|c|c|c|c|c|c|c|}
\hline Disorder & Name of Test & Author & Items & Scales & Reliability & Validity \\
\hline 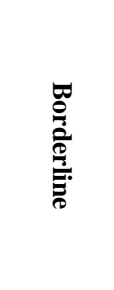 & $\begin{array}{c}\text { Zanarini Rating } \\
\text { Scale For } \\
\text { Borderline } \\
\text { Personality } \\
\text { Disorder } \\
\text { (ZAN-BPD) }\end{array}$ & $\begin{array}{l}\text { Zanarini } \\
\text { (2003). }\end{array}$ & 10 & $\begin{array}{l}\text { 1) Affective } \\
\text { 2) Cognitive } \\
\text { 3) Impulsive } \\
\text { 4) Interpersonal }\end{array}$ & $\begin{array}{c}\text { Internal consistency of the } \\
\text { ZAN-BPD was found to be high } \\
\text { (Cronbach's } \alpha=.85 \text { ) - Zanarini, } \\
\text { 2003. }\end{array}$ & $\begin{array}{l}\text { The convergent validity of the } \\
\text { ZAN-BPD with the scales of the } \\
\text { SCL-90, both of which assess } \\
\text { symptoms in the past week, is high } \\
(p<.001) \text {. This is particularly so } \\
\text { for the overall borderline } \\
\text { psychopathology scores and the } \\
\text { scores pertaining to affective } \\
\text { symptomatology_-Zanarini, } 2003 .\end{array}$ \\
\hline
\end{tabular}

$\begin{array}{ccl}\text { The Revised } & \text { Zanarini, } & \text { 1) Affect } \\ \text { Diagnostic } & \text { Gunderson, } & \text { 2) Cognition } \\ \text { Interview for } & \text { Frankenburg, } & \text { 3) Impulse action } \\ \text { Borderlines } & \text { \& Chauncey, } & \text { patterns } \\ \text { (DIB-R). Interpersonal } & \text { relationships }\end{array}$

The McLean Zanarini, Screening Vujanovic, Instrument for Parachini, Borderline Boulanger, Personality Frances,

Disorder Frankenburg,

(MSI-BPD) \& Hennen
10 $\begin{array}{cc}\text { Borderline } & \text { Butler, } \\ \text { Personality } & \text { Brown, } \\ \text { Disorder } & \text { Beck, \& } \\ \text { Belisham, }\end{array}$

Beliefs Scale Grisham,
Excellent kappas were found in each of the three inter-rater reliability substudies for the vast majority of borderline symptoms assessed by the DIB-R. More specifically, one-third of the BPD symptoms assessed had a kappa in the excellent range and the remaining two-thirds had a kappa in the fair-good range (.57-.73). More specifically, all five dimensional measures of borderline psychopathology had intraclass correlation coefficients in the excellent range for all four reliability substudies. Taken together, the results of this study suggest that both the borderline diagnosis and the symptoms of BPD can be diagnosed reliably when using the DIB-R-Zanarini, Frankenburg, \& Vujanovic, 2002.

Test-retest reliability of the MSI-BPD was found to be good. More specifically, a highly significant correlation was found between the number of items endorsed at Time 1 and Time 2 (Spearman's rho $=.72, p<.0001$ ) (based on the total ranks from the two administrations of the scaleZanarini et al., 2003.

1) Dependent

2) Paranoid

3) Avoidant

4) Histrionic

Themes of dependency,

14 helplessness, distrust, fears of rejection/ abandonment/ losing emotional control, and extreme attention-seeking behaviour.
The internal reliability of the 14 items for the 84 BPD patients was moderately high (alpha $=.89$ ) Butler, Brown, Beck, \& Grisham, 2002.

DSM-IV-TR BPD criteria set as measured by the MSI-BPD demonstrated good concurrent validity_Leung \& Leung, 2009. The MSI-BPD demonstrated adequate criterion validity with the diagnosis of BPD derived from a clinician-administered diagnostic interview-Patel, Sharp \& Fonagy, 2011.

The BPD beliefs scale diagnostic validity among 288 study patients.

-Butler, Brown, Beck, \& Grisham, 2002. 


\section{Continued}

$\begin{array}{ccl} & & \text { 1) Impulsivity } \\ & & \text { 2) Affective } \\ & \text { Instability. } \\ \text { Borderline } & \text { Rawlings, } & \text { 3) Abandonment } \\ \text { Personality } & \text { Claridge, } & \text { 4) Relationships } \\ \text { Questionnaire } & \text { Freeman, } 80 & \text { 5) Self-Image } \\ \text { (BPQ). } & \text { Faulkner, } & \text { 6) Suicide/ } \\ & \text { \& Shelton, } & \text { Self-Mutilation } \\ & \text { (2006). } & \text { 7) Emptiness } \\ & & \text { 8) Intense Anger } \\ & & \text { 9) Quasi-Psychotic } \\ & & \text { States. }\end{array}$

Borderline Pfohl, Blum,

Evaluation of John,

Severity Over McCormick,

$\begin{array}{cc}\text { Time (BEST) } & \text { Allen, \& } \\ \text { Black (2009). }\end{array}$

1) Subscale A

(8 items) addresses problematic thoughts and feelings that are characteristic of BPD (i.e., suicidal thoughts).

2) Subscale B (4 items) addresses problematic or negative behaviours (i.e., problems with impulsive behaviour). Items on these subscales are rated from 1 to 5 , with $5=$ extreme distress, and $1=$ no
The full BPQ is a highly reliable test. Subscale reliabilities are generally satisfactory for scales of this length, though with a few exceptions, particularly

Quasi-Psychotic States. Several

of the subscales show high positive skew, noting that the standard error of skew for the three samples was respectively .18, .16, and .20 . No transformations were performed, and the skewness of the data should

be taken into account when considering the parametric statistics reported in subsequent analysesPoreh, Rawlings, Claridge,

Freeman, Faulkner, \& Shelton. (2006).
Discriminant validity was examined in Sample 2. Pearson correlations were calculated between the BPQ sum score and the total scores on both the MMPI-2 STY subscale

$(\mathrm{r}=.48)$ and the SPQ

$(\mathrm{r}=.45)$. While both coefficients were highly significant, their moderate size suggests satisfactory discriminant validity for the BPQ. Convergent validity was examined

by correlating the

BPQ with the MMPI-2

BPD in Sample 2, yielding a

high correlation of 85 .

The BPQ was correlated with the STB in Samples 3 and 4 , yielding coefficients of .72 and .78 respectively. These results suggest high convergent validity for the BPQ - Poreh, Rawlings, Claridge, Freeman, Faulkner, \& Shelton (2006). distress caused by this symptom. 3) Subscale C, consists of three items that assess the use of positive behaviours learned in therapy (i.e., following through with therapy plans). These items are rated based on frequency over the course of a week.
Test-retest reliability: Correlation between baseline and screening BEST total scores was moderate $(\mathrm{r}=.62, n=130, p<.001)$

The results indicate that the instrument has good test-retest reliability. Internal consistency is excellent, as shown by the moderate to high Cronbach's $\alpha$ coefficients across study visits, which argues strongly for construct validityPfohl, Blum, John, McCormick, Allen, \& Black (2009).
The BEST exhibits face validity by assessing thoughts and behaviours typical of BPD. Evidence for content validity has been indirectly established because the items are derived from the DSM-IV.

At the screening visit, the BEST correlated strongly with the

ZAN-BPD score, SCL-90-R total score, the SAS total score, the CGI severity score, and both the GAS and BDI scores-Pfohl, Blum, John, McCormick, Allen, \& Black (2009). 


\section{Continued}

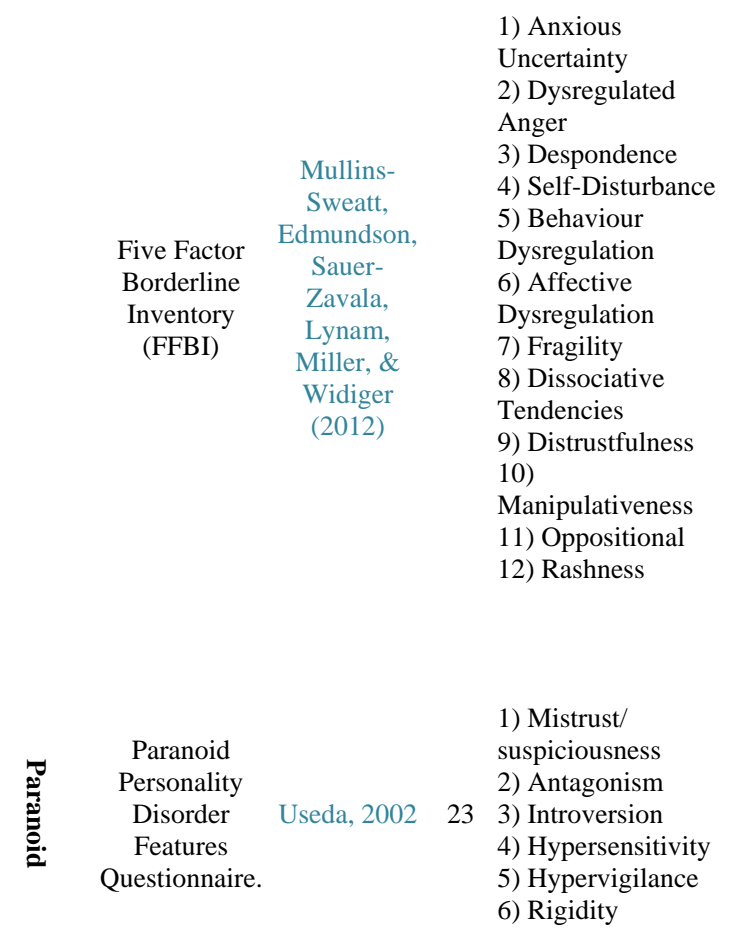

The test-retest reliability of the six PPDFQ scores over a 6-week interval was good, and the hypothesised relationships between the PPDFQ subscales and the five-factor model of personality as well as Livesley's dimensional model of personality pathology were supported-Bernstein \& Useda, 2007.

\section{$\begin{array}{ll} & \\ \text { UN. } & \text { UNABLE } \\ \text { TO FIND }\end{array}$}

The FFBI subscales were shown have good internal consistencyMullins-Sweat, Edmundson, Widiger (2012)

The FFBI subscales were shown to have good convergent, discriminant, and incremental validity-Mullins-Sweat, Edmundson, Sauer-Zavala, Lynam, Miller, \& Widiger (2012)

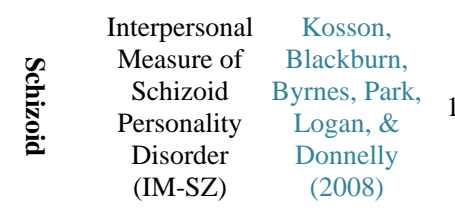

Internal consistency estimates were high, with coefficient alpha equal to .88 . Corrected item-to-total correlations ranged from .40 to .74 , and a mean interitem correlation of .41 suggests homogeneity for the IM-SZ. Interrater agreement was estimated with an average, one-way random effects ICC, based on 123 cases in which interviewer and observer ratings were available, and was acceptable, $r=.69$, indicating that the traits measured are relatively robust across raters. Individual item ICCs were somewhat lower; the mean item ICC was .53-Kosson, Blackburn, Byrnes, Park, Logan, \& Donnelly, 2008.
Results provide preliminary indications that the measure of SZPD correlates with other measures in specific ways that suggest preliminary construct validity. Scores on the IM-SZ appear independent of age, education, and SES yet correlated negatively with IQ. Similarly, IM-SZ scores were generally independent of criminal activity yet correlated in predicted ways with ratings on several components of psychopathy-Kosson, Blackburn, Byrnes, Park, Logan, \& Donnelly, 2008. 


\section{Continued}

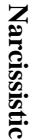

Narcissistic Personality Inventory-16 (NPI-16)
Ames, Rose, \& Anderson 16 (2006).
16
1) Narcissismconsistent

2) Narcissisminconsistent. $\alpha=.72$; mean inter-item correlation =.13-Ames, Rose, \& Anderson (2006).
1) Authority

Narcissistic Personality Raskin \& (NPI-40). Inventory-40 Terry (1988)
2) Exhibitionism

40

4) Entitlement

5) Exploitativeness

6) Self-sufficiency 7) Vanity.
In Raskin \& Terry (1988), alpha composite reliability scores of $.83, .74, .80$, and .90 were calculated.
Narcissistic Personality Inventory
1) Leadership/

54

(each

item

Raskin \& being Hall, 1979 a pair

of

statem

ents)

The

Margolis-

Thomas

Measure of

Narcissism

(M-T)

\section{The}

Margolis-

Thomas

Measure of

Narcissism

Short Verson
Mullins \&

Kopelman, 24 1988)
60 paired statem ents Authority (LA)

2) Superiority/

Arrogance (SA) (SS)
3) Self-Absorption

/Self-Admiration

4) Exploitiveness /Entitlement (EE)
The reliability and validity of the NPI has been established in clinical (e.g., Priftera \& Ryan, 1984) and non-clinical samples (Emmons, 1984; Raskin \& Hall, 1981).
An acceptable level of reliability (.69) was obtained using the abbreviated scale-Mullins \& Kopelman (1988).
Ashby (1978) reported an alpha coefficient of reliability of .81 .
Divergent validity: Narcissism was not significantly correlated with dispositionism.

Convergent validity: Men scored higher in narcissism than women. Predictive validity: Narcissi was significantly and positively correlated with participants' estimates of their own relative performance in a judgment taskAmes, Rose, \& Anderson (2006).

Construct validity: In order to investigate the validity of the seven NPI component scales, we correlated them with the IPAR criterion variables. In the observer domain, five of the seven component scales showed significant positive correlations with the Trait Ranking for Narcissism. These correlations were Authority $(\mathrm{r}=.44, p<.001)$, Exhibitionism $(\mathrm{r}=.42, p<.001)$,

Self- Sufficiency $(\mathrm{r}=.34, p<.01)$, Exploitativeness $(\mathrm{r}=.28, p<.05)$, and Superiority $(\mathrm{r}=.24, p<.05)$ —Raskin \& Terry (1988).
Validity evidence includes the successful differentiation between narcissistic and normal adolescents $(\mathrm{t}=3.93 ; p<.001)$-Mullins \& Kopelman (1988).
The

Narcissistic

Personality

Disorder

Scale (NPDS) shby, Lee, item

\& Duke, true-

1979 false

scale
Solomon (1982) — confirms the validity of the MMPI and are consistent with O. Kernberg's

(1976) emphasis on the impoverishment of object relations in the dynamics of narcissistic personalities and with H. Kohut's (1971, 1976) view of nightmares as a reflection of self-feeling, self-state, or level of narcissistic development. 


\section{Continued}

Murray's

Narcisism Murray, 193820 Scale

The

Hypersensitive Hendin, \&

Narcissism Cheek (1997)

Scale (HSNS).
Cheek and Melchior (1985)

found the alpha reliability

of this scale to be .76 . was .82-Arble, 2008.

The reported reliability of the HSNS was Covert Narcissism good, with alpha coefficients ranging from .72 to .76. Furthermore, the HSNS, the Narcissism-Hypersensitivity Scale, and the NPDS demonstrated significant positive correlations with each other $(\mathrm{r}=.50)$ and negative correlations $(r=-.18)$ with the NPI (Raskin \& Hall, 1979).

1) Entitlement Rage

2) Exploitativeness

3) Grandiose

Pincus, $\quad$ Fansell, Grandios

Pathological Ansell,

Narcissism Cain, Wright,

Inventory (PNI) $\quad$ Cain, Wrig

(2009)

52

4) Self-sacrificing

self-enhancement

5) Contingent

self-esteem

6) Hiding the self

7) Devaluing

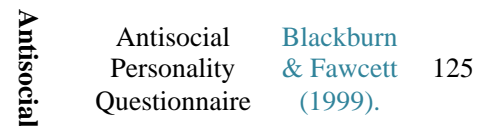

1) Self-Control,

2) Self-Esteem,

3) Avoidance,

4) Paranoid

Suspicion,

5) Resentment,

6) Aggression,

7) Deviance,

8)Extraversion
Cronbach's alpha for the HSNS

The HSNS was found to have a strong negative correlation with the RSES, a measure of self-esteem. Conversely, the HSNS was found to have a strong positive correlation with the measure of social inhibition FNE, a measure of shame (PFQ2), and a measure of masochism

(SDPS).The HSNS also produced a moderate positive correlation with the Social Incompetence scale and a slight positive correlation with the Egocentricity scale. Thus, elevations on HSNS seemed indicative of a wide range of object related distur bances-Arble, 2008.

Comparing correlational patterns for the PNI and NPI, we conclude preliminary evidence exists to support the construct validity of the PNI as a measure of pathological narcissism. Results for the PNI provide additional evidence for its construct validity. Several PNI scales assess grandiose characteristics reflecting, in part, a range of vindictive, domineering, intrusive, and overly-nurturant interpersonal problems. Several PNI scales assess vulnerable characteristics reflecting, in part, cold, avoidant, and exploitable interpersonal problems. We conclude that the associations between the PNI and IIP-C contribute evidence in support of the PNI's construct validityPincus et al., 2009.

The APQ scales clearly differentiate the mentally disordered offender and normal groups, but also discriminate within the offender sample. AMANOVA reveals a highly significant overall difference 87 for the alpha ranges from .77 to .88 for patients, and from .75 to .84 for normals, suggesting satisfactory internal consistencies for all scales-Blackburn \& Fawcett, 1999. between the MI, PD and normal groups $($ Rao's R $(16,712)=15.45$, $p<.0001)$, and univariate ANOVAs indicate significant effects for all scales (Blackburn \& Fawcett, 1999).

\footnotetext{
Psychopathy

Checklist Hare (1980) 22

(PCL)
} 


\section{Continued}

Hare

Psychopathy

Checklist-

Revised

(PCL-R)
1) Callous/

manipulative

interpersonal style

2) Antisocial action

- Harpur, Hare \&

Hakstian, 1989.

1. Primary psychopathy
Psychopathic

Personality

Inventory

Revised

(PPI-R)
Lilienfeld \&

Widows,

(2005).
Kiehl, \&

Fitzpatrick

(1995) 2. Secondary

psychopathy

\section{6}

To assess inter-rater reliability, intra-class correlation coefficients (ICCs; Shrout \& Fleiss, 1979) were calculated for subsamples of subjects rated by more than one rat er (seesample descriptions for №).

They ranged from .78 to .94 ( $M$ $=.86$ ) for a single rating and from .87 to $.97(M=.93)$ for the average of two ratings (computations based on the Spearman-Brown Prophecy

Formula).2 Internal consistency

was assessed by Cronbach's coefficient alpha, which ranged from .85 to $.89(M=.88)$, and by the mean inter-item correlation, which ranged from .23 to $.30(M=.27)$.

These results indicate that the

PCL-R, like the PCL, Can be considered a homogeneous, unidimensional scale (Harpur et al., 1989)—Hare, Harpur, Hakstian, Forth, Hart, \& Newman, 1990.

Cronbach's alphas for the total sample were .85 for the total SRPS, .83 for SRPS factor 1 and .69 for SRPS factor 2-Brinkley, Schmitt, Smith, \& Newman, 2000.

Internal consistency is adequate for the PPI-R Total score and the PPI-R Content scale scores, with coefficient alpha ranging from .78 - .92 for the community/college sample. For the offender sample, internal consistency estimates for the Total and Content scale scores ranged from .72 - .84-Lilienfeld \& Widows, 2005

Antagonism:

1) Distrust

2) Manipulation

3) Self-centeredness

4) Opposition

5) Arrogance

6) Callousness

Lynam, Gaughan, Miller,

The Elemental Miller, Psychopathy MullinsAssessment Sweatt, \& Widiger (2011) ranged from .16 for Arrogance to
Conscientiousness :

1) Disobliged

2) Impersistence

3) Rashness Extraversion:

1) Coldness

2) Dominance

3) Thrill-Seeking Neuroticism:

1) Unconcern

2) Anger

3) Self-Contentment

4) Self-Assurance

5) Urgency

6) Invulnerablility

The associations found between the convergent validity measures and the PCL-R when it was used dimensionally support the validity of the instrument. As predicted, on-Psychoticism, SRPS, SMAST, MPQ-Constraint, and SO scale scores were significantly related to PCL-R scores. Overall, the pattern of results for both the Caucasian and African American women provided support for the convergent validity of the PCL-R in this sample-Vitale, Smith, Brinkley, \& Newman, 2002.

The SRPS and the PCL-R were significantly correlated and both showed similar patterns of correlations to measures of substance abuse and criminal versatility. SRPS was predictive of performance of a passive avoidance task-Brinkley,

Schmitt, Smith, \& Newman, 2000.

Evidence of construct validity was obtained via significant correlations between the PPI-R and self-report measures of pathological and nonpathological personality functioning, DSM-IV Antisocial Personality Disorder, interpersonal problems,

sensation-seeking, substance use, and offense variables-

Lilienfeld \& Widows, 2005

Final scales were fairly reliable. Seventeen of the 18 scales had alpha coefficients above .7; 14 of these were above .8. The average alpha for the 18 scales was .81. The scales were also fairly homogeneous. Average interitem correlations .48 for Dominance, with an average of .34. Average item-total correlations ranged from .31 for Arrogance to .62 for Thrill-Seeking, with an average of .51 .
Concurrent validity was shown by correlations with other self-report psychopathy measures; SRP, LSRP, PPI-R. The measure contains two validity scales: Infrequency scale, and a Too Good to Be True scale. It has an alpha level of .95. 


\section{Continued}

Invenotry of

Callous-

Unemotonal Frick (2004) 24 Traits
Careless

Callous

Unemotional

Uncaring
.81 (Kimonis, Frick,

Skeem, Marsee, Cruise,

Munoz, Aucoin, \& Morris, 2008b)
The coefficient alpha $=$
Evidence of concurrent validity is given by significant positive correlations with external criteria: positive correlations with proactive and reactive aggression,

violent and non-violent delinquency and sex offenders. It is negatively correlated with empathy and positive affect.
.
1) Ideas of reference

2) Excessive social

anxiety.

3) Odd beliefs or

magical thinking.

Schizotypal

Personality

Questionnaire

(SPQ)

Schizotypal

Personality

Questionnaire-

Brief (SPQ-B)

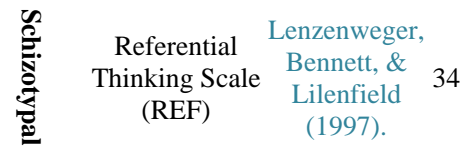

4) Unusual

Raine (1991) 74 perceptual

5) Odd or eccentric

behaviour.

6) No close friends

7) Odd speech.

8) Constricted affect.

9) Suspiciousness.

1) Interpersonal

Raine \&

Deficits

Benishay 22 2) Cognitive-Perceptual

(1995).
Deficits

3) Disorganisation.
The REF displayed good internal consistency $(\alpha$

$=.86)$ for the total sample-Lenzenweger, Bennett, \& Lilenfield (1997).
High scores on the REF are associated with elevated scores on measures of perceptual aberration, magical ideation, and schizophrenia-related psychometric deviance, all measures known to be related to schizotypy, which is suggestive of convergent validity-Lenzenweger, Bennett, \& Lilenfield (1997).

\author{
High internal reliability \\ (.91), test-retest \\ reliability (.82) \\ —Raine (1991).
}

High convergent validity (.59 to .81), discriminative validity (.63) and criterion validity (.68)—Raine (1991).
In the present sample, the Correlations between SPQ-B total and KR-20 internal consistency subscale scores and the derived SCID-II reliability coefficient for SPD criteria scores were examined next the full SPQ-B was .83 in a subsample of participants for whom (.82 in biological relatives SCID-II data were available (from the first and .83 in non-psychiatric study; $\mathrm{n}=58$ ). The SPQ-B total score was comparison participants) significantly correlated with the SCID-II
-Compton, Chien, Bollini, 2007.
SPD criteria total score $(p=.49$, pb.001).

1) Childhood

Personality thinking.

2) Adolescent Personality

3) Social Isolation

4) Interpersonal

Sensitivity

5) Social Anxiety

Structured

Interview for

Kendler,

6) Ideas of Reference

Schizotypy Lieberman, \& 25 8) Remarks

(SIS)

Walsh (1989).
9) Suspiciousness
10) Restricted Emotion
11) Magical Thinking
12) Illusions
13) Psychotic-like
phenomena
14) Derealisation
15) Antisocial Behaviour
16) Impulsivity 


\section{Continued}

OxfordLiverpool Inventory of Feelings and Experiences (O-LIFE)

Mason,
Claridge, \&
Jackson
(1995)
experiences 2) Cognitive disorganisation 3) Introvertive anhedonia 4) Impulsive non-conformity
Foa,

ObsessiveCompulsive Inventory Short Version (OCI-R)

Huppert, Leiberg, Kichic, Hajcak, \& Salkovskis, (2002).
1) Washing 2)Checking

18 ) Ordering 4) Obsessing 5) Hoarding 6) Neutralising
Test-retest reliability for the controls, distress (OCD, $\mathrm{r}=.87$; controls, $\mathrm{r}=.89$ ) and frequency (OCD, $r=.84$; controls, $r=.90$ total scores.

1) Washing

2) Checking

3) Doubting

ObsessiveCompulsive Inventory (OCI)
Foa, Kozak, Salkovskis, Coles, \& Amir (1998).
The test-retest reliability for the subscales exceeded .80 , with the $=.77$ ) and Ordering frequency
4) Ordering

5) Obsessing

6) Hoarding

7) Mental

Neutralising
Test-retest reliability: Spearmans correlations- Patients diagnosed with OCD ranged from .74 to .91 . Nonanxious controls ranged from .57 to .87Reid, Rosen, Arnold, Larson, Mason, Murphy, Storch, 2011.
The short forms had higher predicted by the Spearman-Brown formula, which suggests that they retained the relatively more scales-Winterstein,

Silvia, Kwapil, Kaufman, 2011.

All scales have highly as assessed by coefficient alpha. cale $1, \alpha=.89$ $2, \alpha=.87$

$3, \alpha=.82$ Mason, Claridge, \& Jackson (1995) exception of Ordering distress ( $\mathrm{r}$ scores $(\mathrm{r}=.79)$ in the OCD sample and the Doubting distress $(\mathrm{r}=.77)$ and Hoarding distress

$(r=.68)$ scores in the control sample-Foa, Kozak, Salkovskis, Coles, Amir, 1998.
The positive and negative symptom dimensions correlated modestly ( $\mathrm{r}=.13)$-Winterstein,

Silvia, Kwapil, Kaufman,

Reiter-Palmon \& Wigert, 2011.
Results indicate that the OCI-R is a psychometrically sound and valid measure of OCD and its various symptom presentations. The instrument also evidenced good convergent validity, and performed well in discriminating OCD from other anxiety disorders The OCI- $\mathrm{R}$ is recommended as an empirically validated instrument that can be used in a range of clinical and research settings for research on OCD-Abramowitz

\& Deacon, 2006.

Discriminative validity: Comparisons of means for the total distress score revealed that the OCD group reported greater distress on the OCI than did the other 3 groups.

Comparisons of means revealed that the OCD group reported more frequent OCD

symptoms than did the remaining 3 groups on all but the Hoarding subscale. Convergent validity: The validity of the OCI total distress and frequency scales was assessed by correlating (Pearsons correlations) the OCI scores of the OCD patients with scores obtained on other measures of OCD symptoms: Y-BOCS, CAC, MOCI. For the OCD sample, the coefficients were quite high, ranging from .41 to .93 with MOCI—Foa, Kozak, Salkovskis, Coles, Amir, 1998. 


\section{Continued}

\begin{tabular}{ccc} 
& \multicolumn{1}{c}{ 1) Overestimation } \\
& of threat. \\
& 2) Tolerance of \\
Obsessive & uncertainty. \\
Beliefs & Steketee \& & 87 \\
Questionnaire & Frost, (2001) & $\begin{array}{l}\text { 3mportance of } \\
\text { thoughts. }\end{array}$ \\
(OBQ) & 4) Control of thoughts. \\
& 5) Responsibility. \\
& 6) Perfectionism.
\end{tabular}

The

Vancouver

Obsessional-

Compulsive

Inventory

(VOCI)
Cronbachs alpha for those with OCD and control samples were between .80 and .96-

Obsessive Compulsive Cognitions Working Group, 2001.

The multivariate effect was significant, Wilks' Lambda =

$.039, \mathrm{~F}(30,1806)=75.28$, $p<.05$. Univariate analyses were then conducted for each subscale. All of these one-way ANOVAs were also significant. Follow up

Student-Newman-Keuls tests showed that the OCD group scored significantly higher than the other four groups in all cases with one exception: OCDs did not score higher than anxious controls on Perfectionism. Student controls scored higher than all community controls on Overestimation of Threat, and higher than Greek community controls on Responsibility. These results support the known groups validity of the scales by distinguishing people who have OCD from those who do not-Sica, Coradeschi, Sanavio, Dorz, Manchisi \& Novara (2004).

Scores of the VOCI and its subscales demonstrated acceptable to excellent internal consistency

$$
(.81 \leq \alpha \leq .95)
$$

—Gönner, Ecker, Leonhart, \&

Limbacher 2010b. The VOCI and its subscales appear to have excellent test-retest reliability in the OCD sample, with all coefficients .9 or above, and with the one-sided .95 confidence interval $>.81$ in all cases, despite, on average, a long test-retest interval. For the students, on the other hand, test-retest reliability is poor, ranging from .5 to .6 . In the student sample, these low correlations may be due to range restriction. Most of the students had mean VOCI item scores between 0 and 1 , with the exception of four participants, who appeared to be bivariate outliers.

Excluding the four outliers improved the test-retest correlations for some scales (e.g., VOCI total, $r=.62, p<.001)$, but not others (e.g., VOCI Checking, $r=.44$ ).

-Thordarson, Radomsky, Rachman, Shafran, Sawchuk \& Hakstian, 2004.
The OCD group scored significantly higher than the other groups on the VOCI total score, Contamination, Checking, Just

Right, and Indecisiveness subscales.

The OCD group scored significantly higher than the non-clinical controls but not the A/D control group on the Obsessions and Hoarding subscales-Thordarson,

Radomsky, Rachman, Shafran,

Sawchuk \& Hakstian, 2004.

Convergent and discriminant validity: OCD sample-Total score highly correlated with other multidimensional self-report measures of OCD and moderately correlated with measures of anxiety, depression and worry. Convergent and discriminant validity were excellent for the Contamination and Checking subscales, but weaker for Obsessions. Discriminant validity of Hoarding was excellent, while its convergent validity was not examined-Gönner, Ecker,

Leonhart, \& Limbacher, 2010 


\section{Continued}

$\begin{array}{ccc}\text { Maudsley } & & \text { 1) Washing } \\ \text { Obsessional- } & \begin{array}{c}\text { Hodgson \& } \\ \text { Compulsive }\end{array} & \begin{array}{c}\text { Rachman, } \\ \text { 2) Checking }\end{array} \\ \begin{array}{c}\text { Inventory } \\ \text { (MOCI) }\end{array} & \text { (1977). } & \text { 4) Downess } \\ & & \end{array}$

PaduaInventoryPalatine Revision (PI-PR) Inventory (PI)

Leyton Obsessional Inventory
1) Impaired Mental Control

2) Contamination

Sanavio (1988)

60 3) Checking

Behaviour

4) Loss of Control

of Actions

(factors)

Cooper

(1970)
69 1) Resistance Scale. 2) Inference Scale.
1). Contamination

2) Checking

3) Obsessions

Ecker, Leonhart, \& Limbacher, (2010).

a) Immoral

b) Harming

4) Hoarding

5) Symmetry and

Ordering
Test-retest reliability, 50 participants, completing the questionnaire one month apart ( $\mathrm{r}=.80$ )—Hodgson \& Rachman, (1977).
Scores of the 30-item total scal and of all symptom subscales showed good to excellent internal consistency $(.82 \leq \alpha \leq .95)$ Gönner, Ecker, Leonhart \& Limbacher, 2010.

Convergent validity: Scores of the total scale and the five symptom subscales demonstrated excellent convergent validity. All VOCI-R subscales showed moderate to high correlations with the OCI-R total

scale $\left(\mathrm{r}_{\mathrm{s}}\right.$-range $\left.=.47-.57\right)$ and with the PI-PR total scale $\left(\mathrm{r}_{\mathrm{s}}\right.$-range $=.43-.55)$.

Discriminant validity: of the VOCI-R total scale $\left(\mathrm{r}_{\mathrm{s}}\right.$-range $=.34-.39$ ) and the five symptom scales with measures of depression, anxiety and worries $\left(\mathrm{r}_{\mathrm{s}}\right.$-range $=.07-.31$ ) indicate only a low to moderate construct overlapGönner, Ecker, Leonhart, \& Limbacher 2010

For 30 obsessionals, we had Leyton Inventory Scores (Cooper, 1970) and found that our "total obsessionality” score correlated significantly with the

Leyton Symptom Score

(.6)-Hodgson \& Rachman, (1977).

In the OCD sample the PI-PR and its subscales demonstrated good to excellent convergent validity with corresponding OCI-R scales. On the whole, the PI-PR and its

1) Contamination/ The total scale and all subscales Washing

Gönner, Ecker \& Leonhart, (2010).

2) Checking 24 ) Numbers

24 4) Dressing/ Grooming 5)Rumination

6) Harming Obsessions/ Impulses had acceptable to excellent

internal consistency $(.78 \leq \alpha \leq .93)$ Acceptable corrected item-total correlations $(\mathrm{r}>.40)$ were found for the PI-R (with one exception: Rumination subscale, Item 121)Gönner, Ecker \& Leonhart, 2010
The $\alpha$ coefficient was .90 in male and .94 in female participants-Coles (2003).

Test-retest correlations were 0.78 for males, and .83 for females

who filled out the inventory twice at a 30-day interval-Sanavio (1988).

The Leyton Obsessional Inventory (LOI) is a card-sort task that has shown good reliability and validity estimates (Cooper, 1970; Taylor, 1995) subscales demonstrated very satisfying divergent validity with measures of depression, anxiety, and worries in the OCD sample, except for PI-PR Rumination and PI-PR Harming Impulses and Obsessions.

In the anxiety disorder sample, the PI-PR and its subscales demonstrated good to excellent convergent validity with corresponding OCD scalesGönner, Ecker \& Leonhart, 2010

When assessing the convergent and divergent validity of the PI substantial correlations were found between related scales of the PI and the MOCI. The substantial correlation between the total PI scores and the two subscales of the SCL-90-R, Sensitivity and

Hostility, are in line with the findings reported in Millar (1983) —van Oppen (1992).

"Within the limits imposed by these selected criterion groups, this inventory is valid, since it differentiates between the obsessional patients and the normals with very little overlap" -Cooper, 1970. 


\section{Continued}

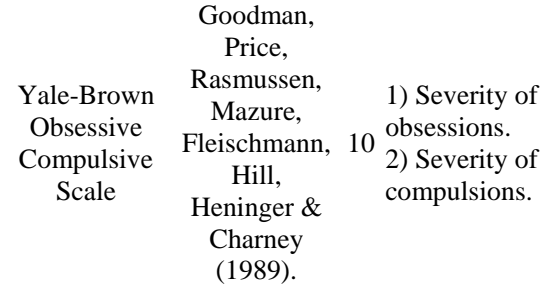

Obsessive Bouvard, Compulsive Mollard, Thoughts Cottraux, Checklist Guerin, (OCTC) (1989)

1) Checking

3) Washing
Inter-rater reliability estimated to be excellent (obsessions subtotal, $\mathrm{r}$ $=.97$; compulsions subtotal, $\mathrm{r}$ $=.96$; total score, $\mathrm{r}=.98)$-Foa, Kozak, Salkovskis, Coles, Amir (1998).

The Cronbach coefficient of internal consistency was computed for the 28 items for each group separately. Reliability was satisfactory (OCD patients = .88; agoraphobic patients $=.84$ and control subjects $=.89$ ). Then the Cronbach coefficient of internal consistency was computed for each factor

subscale across the three groups: - checking subscale (10 items): OCD patients $=.87$; agoraphobic patients $=.88$ and control subjects $=.79$.

28 2) Responsibility
The total Yale-Brown Scale score was significantly correlated with two of three independent measures of obsessive-compulsive disorder and weakly correlated with measures of depression and of anxiety in patients with obsessive-compulsive disorder with minimal secondary depressive symptoms. Results from a previously reported placebo-controlled trial of fluvoxamine in 42 patients with obsessive-compulsive disorder showed that the Yale-Brown Scale was sensitive to drug-induced changes, and that reductions in Yale-Brown Scale scores specifically reflected improvement in obsessive-compulsive disorder symptoms. Together, these studies indicate that the 10-item Yale-Brown Scale is a reliable and valid instrument for assessing obsessive-compulsive disorder symptom severity, and that it is suitable as an outcome measure in drug trials of obsessive-compulsive disorder-Goodman, Price,

Rasmussen, Mazure, Fleischmann, Hill, Heninger \& Charney (1989).

Spearman rank correlations were used to compute convergent validity in a sub-group of obsessive compulsive patients ( $\mathrm{r}-96)$. The Obsessive Compulsive Thoughts Checklist correlated positively with the Compulsive Activity Checklist (rho - .62; $p<.0001$ ).

The total score was also positively correlated with the Yale-Brown Obsessive Compulsive Scale (YBOCS total scale: rho - .42; $p$ $<.0001$; YBOCS obsession scale: rho - .40; $p<.0001$; YBOCS compulsion scale: rho .37; $p$

$=.0002$ ). The factor structure was studied both on the sample which included agoraphobic patients and controls ( $n$ - 141) and on the

- responsibility subscale (11 items):

OCD patients $=.84$; agoraphobic obsessive compulsive patients only patients $=.83$ and control subjects $(n=122)$. In both analyses, three identical factors were found: - factor 1: checking/ $=.68$.

- washing subscale (7 items): OCD patients $=.87$; agoraphobic patients

$=.81$ and control subjects $=.59$ -

Bouvard, Cottraux, Mollard, Arthus, Lachance, Guerin, Sauteraud \& Yao (1997). perfectionism-orderliness - factor 2: responsibility/dread of harming others

- factor 3: washing/contamination. Results support the validity and the internal consistency of the Obsessive Compulsive Thoughts Checklist-Bouvard, Cottraux,

Mollard, Arthus, Lachance, Guerin, Sauteraud \& Yao (1997). 


\section{Continued}

\begin{tabular}{|c|c|c|}
\hline & & 1) Perfectionism \\
\hline & & 2) Fastidiousness \\
\hline & & 3) Punctiliousness \\
\hline & & 4) Workaholism \\
\hline & Samuel, & 5) Doggedness \\
\hline Obsessive- & & 6) Ruminative \\
\hline Compulsive & Lynam, & Deliberation \\
\hline Inventory & Miller, \& & 7) Detached Coldness \\
\hline (FFOCI) & Widiger & 8) Risk Aversion \\
\hline & & 9) Constricted \\
\hline & & 10) Inflexibility \\
\hline & & 11) Dogmatism \\
\hline & & 12) Excessive Worry \\
\hline
\end{tabular}

Dependent Tyrer,

Personality Morgan, \&

(DPQ) (2004).
The 12 scales demonstrated

convergent correlations

with established measures of OCPD and the

FFM-Samuel, Riddell,

Lynam, Miller, \&

Widger, 2012.

12) Excessive Worry

\footnotetext{
Dependent

Personality Huber (2005) Inventory (DPI)

1) Difficulty making everyday decisions. 2) Needs others to assume responsibility for most major areas of life. 3) Has difficulty expressing disagreement with others because of fear of loss or support from others. 4) Has difficulty initiating projects or doing things on own because of lack of self-confidence in judgment or abilities rather than a lack of motivation or energy. 5) Goes to excessive lengths to obtain nurturance and support from others to the point of volunteering to do things that are unpleasant. 6) Feels uncomfortable or helpless alone because of exaggerated fears of being unable to care for self. 7) Urgently seeks another relationship as a source of care and support when a close relationship ends. 8) Is unrealistically preoccupied with fears of being left to take care of self.
}

Minnesota

Multiphasic

Personality Ben-Porath, Inventory-2 Hostetler,

Social Introver- Butcher, \& sion Subscales Graham, 1989 (MMPI-2 Si1,

2, 3)
The 12 scales obtained strong discriminant validity with respect to facets from other five factor model domains and OCPD for predicting a composite measure of obsessive-compulsive symptomatology-Samuel, Riddell, Lynam, Miller, \& Widger, 2012.

The DPQ was also a good predictor of the diagnosis of dependent personality disorder, with sensitivity, specificity, predicted positive, and predicted negative accuracies of $87 \%$. -Tyrer, Morgan, \& Cicchetti (2004).
The internal consistency of the revised Dependent Personality Inventory (DPI-R) to .90, making the test highly reliable. -Huber (2005).
Construct validity is satisfactory for the DPI as our results support the findings of previous studies that suggest two distinct constructs form dependent personality disorder —Gude, Hoffart, Hedley \& Ro, 2004.
Respective reliabilities for Si1, Si2, and Si3 of .82, .77, and .77 for college men and .82, .75 , and .77 for college women-Ben-Porath 
DSM-III-R. The PDQ-R consists of 152 items that are also answered by a forced choice true/false paradigm. Uehara, Sakado and Sato (1997) found test-retest reliabilities ranging from .76 to 1.0. Hyler, Skodol, Oldham, Kellman and Doidge (1992) found satisfactory levels of sensitivity and moderate levels of specificity for most of the PDs. They did note however that the PDQ-R did yield many false-positives, concluding that this cannot be used diagnostically as a replacement of a structured interview.

The Coolidge Axis-II Inventory (CATI; Coolidge, 1984) is a 225 item self-report scale, measuring DSM-III-R PDs (13 PDs) alongside three axis-I disorders (anxiety, depression and brain dysfunction). Coolidge and Merwin (1992) found an average test-retest reliability of .90 and a Cronbach Alpha level of .71 suggesting that this instrument is highly reliable in its efficacy to predict PDs. Watson and Sinha (1996) did find some gender bias regarding the antisocial PD scale and age biases for younger respondents (17 - 24 years old) in comparison to older respondents (25 - 57 years old). Ramanaiah and Sharpe (1998) demonstrated through varimax rotation that each of the CATI's scales could be mapped onto the five factor model of personality, providing support for its dimensional nature. Silberman, Roth, Segal and Burns (1997) compared the convergent validities between the CATI and the Millon Clinical Multiaxial Inventory II (MCMI-II; Millon, 1983) in a sample of elderly inpatients. Generally they found that validities between the two widely ranged, however 7 out of the 13 PDs had coefficients higher than .54 .

The Short Coolidge Axis-II Inventory (SCATI; Coolidge, 2001) is a 70 item abbreviation of the CATI. Watson and Sinha (2007) found internal reliabilities to range from .46 to .72 (averaging at .61), which is impressive in comparison to the CATI's (.70 to.86, averaging at .78; Watson and Sinha, 1996). Much like the CATI, evidence for gender biases in the SCATI were also found, with Cohen effect sizes ranging from .25 (schizoid PD) to 1.13 (sadistic). The authors were also able to map the SCATI's factors onto Eysenck and Eysenck's (1975) PEN model of personality. Lastly, the authors used confirmatory factor analysis (CFA) to demonstrate that the SCATI and the CATI are convergent.

The Millon Clinical Multiaxial Inventory-III (MCMI-III; Millon, Millon, Davis \& Grossman, 2009) is a 175 item questionnaire that consists of 14 PD scales (11 moderate PD scales and 3 severe personality pathology scales), 10 clinical syndrome scales, five correction scales (designed to identify random response styles and modifying indices) and 42 Grossman personality facet scales. Participants respond via true/false answers. There are two earlier versions of the MCMI-III, the MCMI (Millon, 1983) and the MCMI-II (Millon, 1987) that hold acceptable psychometric properties, but for the purpose of this review the MCMI-III will be of primary focus due to its accordance to the DSM-IV. One standout feature of MCMI-III is its theoretical anchoring.

The MCMI-III is built upon four domains of evolutionary theory: existence, adaptation, reproduction and abstraction. Another differentiating factor of the MCMI-III is that diagnoses are made based on respondents scoring higher than the base rate score of 84. Retzlaff (1996) investigated the MCMI-III's diagnostic validity and found that the instrument's positive predictive power varied widely. For example, validity coefficients ranged from .00 (sadistic personality) to .27 and .32 (narcissistic and histrionic respectively). This suggested that the instrument's predictive validity could be improved. Millon, Davis and Millon (1997) however report very different positive predictive validities, ranging from .33 (delusional) to .93 (drug abuse), with an average of .64 across all PD and axis 1 disorders. Millon et al. (1997) also report Kappa levels ranging from .23 (anxiety) to .84 (paranoid), suggesting highly discrepant levels of test-retest reliability.

The Personality Beliefs Questionnaire (PBQ; Beck \& Beck, 1991) is a self-report questionnaire that measures beliefs associated with 9 DSM-III-R PDs across 126 items. Like the MCMI-III, the PBQ is based on a foundation of cognitive theory whereby disorders are maintained by maladaptive thinking styles. Trull et al. (1993) found that the PBQ had alphas ranging from .77 to .93, with test-retest reliabilities from .63 (passive aggressive) to 82 (paranoid)—a finding further supported by Connan et al. (2009). The PBQ has also good discriminant validity, with psychiatric patients scoring significantly higher on the scale associated with their mental illness in contrast to any other scale on the questionnaire (Beck et al., 2001). This finding was also replicated by Jones, Burrell-Hodgson and Tate (2007) who compared the PBQ to MCMI-III diagnoses on 164 psychiatric patients. In addition to the PBQ, Butler, Beck and Cohen (2007) created a short form of the PBQ (PBQ-SF) that features only 65 items and measures all Axis II PDs except borderline PD. Similarly to the PBQ, the PBQ-SF has been found to hold desirable psychometric properties: Cronbach alphas ranged from .81 to .92, and test-retest correlations ranged from .57 to .82. Both the PBQ and the PBQ-SF seem to have the most impressive levels of reliability and validity in comparison to the other self-report instruments reported in this paper, with the added bonus of having a detailed theoretical grounding. The PBQ-SF is of use to both clinicians (when it is not feasible to 
administer the PBQ) and academics (the PBQ-SF can be easily inserted into a battery of self-report instruments without taking too much time or space). A recent review of the scale was very positive (Bhar, Beck, \& Butler, 2011).

Minnesota Multiphasic Personality Inventory for the DSM-III (MMPI; Morey, Waugh, \& Blashfield, 1985). The MMPI features a scale for each of the DSM-III PDs measured via 556 items. The original authors found good levels of internal consistency ranging from .67 (compulsive) to .85 (avoidant). When Schuler, Snibbe and Buckwalter (1994) investigated the MMPI's concurrent validity by correlating its scales with diagnoses made via the MCMI, only five out of the eleven MMPI scales were positively correlated: schizoid, avoidant, dependent, histrionic and narcissistic. Although this suggests some evidence of concurrent validity, it is limited at best. Much like the CATI, clinicians and academics wanting to use this instrument should be aware that it is constructed around the DSM-III.

The Omnibus Personality Inventory (OMNI; Loranger, 1994, 2002) is a 375 item self-report instrument that assesses all ten DSM-IV PDs, and also the traditional five-factor model and 25 normal personality traits (e.g. warmth, trustfulness, and modesty). A practical strength of the OMNI is that it is used in conjunction with computer software that can automatically generate a comprehensive evaluation report. It can therefore be deployed in a variety of clinical, occupational and academic settings easily and quickly. Despite this, the instrument is not widely used. It has shown to demonstrate acceptable levels of internal consistency and reliability (Lenzenweger, Loranger, Korfine, \& Neff, 1997).

The Schedule for Nonadaptive and Adaptive Personality (SNAP; Clark, 1993) is a 375-item questionnaire that consists of 15 scales; 12 of which are focused on maladaptive traits and the remaining scales assess negative and positive temperament and disinhibition. The original SNAP assessed the DSM-III-R PDs and the SNAP-2 assesses both the 10 primary PDS in DSM-IV and also the PDs in the appendix. The SNAP is designed to measure dimensional correlates to DSM-IV PDs, and has also 11 diagnostic scales for the DSM-IV-TR PDs. Clark (1993) found that the SNAP scores correlated on average .54 to DSM-IV diagnoses-a coefficient surprisingly high for a self-report instrument. Melley, Oltmanns and Turkheimer (2002) investigated the test-retest reliability and predictive validity of the SNAP; there were satisfactory levels of temporal stability (.58 to .81 ), however the authors found mixed support for its predictive validity. The SNAP scores did modestly predict cluster A and C PD onset. SNAP-2's predictive validity has been shown to be higher than both the NEO PI R and the DSM-IV diagnoses themselves (Morey, Hopwood et al., 2007, 2012).

The Wisconsin Personality Disorder Inventory-IV (WISPI; Klein et al., 1993; Klein \& Benjamin, 1996). The WISPI-IV is an updated version of the WISPI-III and WISPI-III-R (Klein et al., 1993) self-report inventories using 204 items to assess DSM-IV criteria for PDs relying on an analysis of DSM items according to Benjamin's Structural Analysis of Social Behavior model (SASB, Benjamin, 1996). Its validity with the SCID-II has been examined in adult psychiatric inpatients, showing poor convergence at the level of categorical diagnoses, but better convergent and discriminant validity for 5 out of 11 WISPI-IV dimensional scales (Smith et al., 2011).

The Personality Assessment Inventory (PAI; Morey, 1991), is a 344 item questionnaire presented with a four point Likert scale, used in both clinical and community settings. It measures 22 non-overlapping scales that are arranged into four clusters: clinical (this comprises DSM-IV PDs alongside addictive disorders), interpersonal (this seeks to measure interpersonal strategies), treatment (this cluster provides insight into the various efficacies of certain clinical treatments in relation to the individual's personality, or other risk factors not held in the domain of clinical disorders) and validity (attempts to identify "faking good", defensive or exaggerated responses to the questionnaire). Essentially it aims to assess Borderline and Antisocial Personality Disorder.

Boone (1998) found acceptable levels of internal consistency for the clusters (averaging .82) and the subscales (averaging .66). Some research has questioned its validity. Slavin-Mulford et al. (2012) researched the inventory's convergent and discriminant validity by correlating PAI scales with the prevalence of life-events in psychiatric patients. The majority of the scales did hold meaningful correlations with at least one life-event, except for the mania and anxiety scales. The aforementioned research suggests that despite the self-report methodology, the PAI has some utility in a variety of environments. It is important to note that this instrument is not designed to be used as a tool for diagnosing disorders like the DIPD-IV; instead it provides an insight into the individual's personality and temperament in a variety of contexts.

The Standardised Assessment of Personality: Abbreviated Scale (SAPAS; Moran et al., 2003) is an eight item screening interview that aims to provide a dimensional score as to whether the individual has a PD in general, rather than screening for specific disorders. Scores can range from 0 to 8 ; any scores higher than 3 indicate the 
high possibility of a PD. The benefit of such a short interview is that it can be used in clinical environments when pressed for time. Hesse and Moran (2010) compared SAPAS scores with a variety of comprehensive personality inventories and found that SAPAS scores did regress on most DSM-IV PDs when controlling for demographic variables, suggesting convergent validity. However SAPAS scores were less likely to be associated with cluster B disorders (Antisocial, Histrionic and Borderline).

The Hogan Development Survey (HDS; Hogan \& Hogan, 1997) is a self-report scale that renames the DSM-IV PDs into lay terms and is also contextualised for the work environment. Just like the Hogan Personality Inventory (HPI; Hogan \& Hogan, 1992), the HDS is not a clinical instrument; instead it is mainly used for coaching, leadership development, and personnel selection. Furnham, Trickey and Hyde (2012) found various facets of the HDS to predict work success. Furnham et al. also found that the 11 scales can be clustered into three formations that are similar to clusters A, B, and C suggested by the DSM-IV. Over a dozen published studies have attested to its reliability, validity and dimensional structure (De Fruyt, Wille, \& Furnham, 2013b).

The Tendances Dysfonctionelles-12 (TD-12; Rolland \& Pichot, 2007) inventory examines the DSM-IV PDs, supplemented with the passive-aggressive and the depressive PDs. TD-12 is developed for the assessment of personality tendencies that may potentially harm and affect personal, social and professional functioning and is, like the HDS, mostly used in personnel selection and professional development contexts. The significance of the description of these personality tendencies for understanding behavior and performance at work is further described by Furnham and Taylor (2004) and Miller (2008).

\subsection{Multidimensional Measures Targeting Categorical PDs}

A series of dimensional approaches towards the description of personality pathology have been suggested as alternatives to the categorical DSM-IV PD diagnoses, including general dimensional models such as the FFM and more specific personality pathology dimensional representations like the SNAP, the DAPP-BQ or the DSM-5 trait model described in DSM-5 Section 3. Although these approaches advocate a dimensional instead of a categorical description of personality (pathology), in-between proposals to bridge categorical and dimensional diagnostics were proposed for most of these models. How such dimensional models translate into categorical PDs is described here.

FFM-based measures of Axis-II PDs. Widiger and Costa (2013) recently updated and summarized the available evidence for using a general trait model like the FFM for the description of PDs relying on the assumption that the distinction between general traits and personality pathology reflects more a quantitative than a qualitative difference (Simms \& Clark, 2006). Samuel and Widiger (2008), for example, recently meta-analyzed the associations between FFM facets and DSM-IV PDs, demonstrating that most PDs could be described in terms of a particular set of FFM facets. Miller and colleagues (2005) corroborated on such findings and proposed an easy-to-use system to describe DSM-IV PDs in terms of aggregates of a specific set of FFM facets per PD. Scoring in a more extreme range on such a FFM PD count (for example 1.5 SD beyond the mean) is considered indicative of a specific PD, requiring further attention. Bastiaansen, Rossi and De Fruyt (2012) examined the concurrent validity of different FFM PD counts in an attempt to optimize this proposed scoring system. The utility of these FFM PD counts has been further supported in the meantime for both clinical and professional developmental diagnostic purposes. Miller and colleagues (2010) demonstrated the utility of this system for clinical decision making, whereas Wille et al. (2013) and De Fruyt et al. (2009, 2013b) investigated the applicability of the counts to screen for aberrant traits observable in the working population to identify dark side personality tendencies that may hinder performance or functioning at work.

DSM-5 trait model. A trait-set for describing personality pathology structured under the five broad dimensions of Negative Affectivity, Detachment, Disinhibition, Antagonism and Psychoticism is described in section 3 of DSM-5 (APA, 2013) for further review and evaluation. Although the labels for this five-factor structure are different from the defining dimensions of the FFM, there is strong support that at least four dimensions are conceptually and empirically related to the FFM dimensions, with some disagreement on the association between the FFM Openness to experience and the DSM-5 Psychoticism dimension (De Fruyt et al., 2013a). Krueger et al. (2012) developed the Personality Inventory for DSM-5, assessing 25 traits that can be combined to assess either six categorical PDs (borderline, avoidant, schizotypal, antisocial, obsessive-compulsive and narcissistic) or lead to a diagnosis of personality disorder trait-specified, when patients demonstrate elevated trait levels. 


\section{Assessments of Single Personality Disorders}

The review of instruments assessing single PDs follows the order in which PDs are listed in DSM-5

\subsection{Paranoid}

There is much debate surrounding the paranoid personality disorder due to its shared symptomology with disorders such as schizotypal PD, narcissistic PD, and schizophrenia. The paranoid PD is marked by an entrenched mistrust towards others. Only one instrument was found that specifically diagnoses the paranoid PD.

The Paranoid Personality Disorder Features Questionnaire (Useda, 2002) is a 23-item inventory that measures six scales: mistrust, antagonism, introversion, hypersensitivity, hyper vigilance and rigidity. The authors intend for the six dimensions to closely map the current literature and DSM-IV criteria. There is a shortage of papers showing the efficacy of the instrument. However the original author did find that the instrument showed satisfactory test-retest reliabilities after a six-week period.

\subsection{Schizoid}

There appears to be only one measure of the schizoid PD. This may be due again to the controversy between distinguishing between schizoid and schizotypal PDs and schizophrenia. Nevertheless, the DSM-5 defines schizoid PD to be characterised by a lack of interest in social relationships and a stunted range of emotions. This contrasts with schizotypal PD that is characterised by unusual thinking styles and paranoia.

The Interpersonal Measure of Schizoid Personality Disorder (IM-SZ) (Kosson, Blackburn, Byrnes, Park, Logan, \& Donnelly (2008)) consists of 12 items that measure various aspects of interpersonal interaction (e.g. rapport, absence of spontaneity in speech, poor interpersonal hygiene, and lack of verbal responsiveness). In two cross-validation studies (total $\mathrm{N}=731$ ), acceptable levels of internal reliability were achieved (.88), with inter-rater agreement (the inventory was completed after a semi-structured interview that was focused on the individual's quality of held interpersonal relationships) to yield a Kappa level of .69. The authors also found the measure to hold good construct validity, but do call for further validations.

\subsection{Schizotypal}

As already mentioned there is a difference between schizoid and schizotypal PD (STPD), with the latter characterised by abnormal thought patterns, paranoia, and referential thinking. Our review identified seven specific measures of STPD, with each measure offering varying levels of, or focusing on specific, dimensions. Of all the instruments reviewed, the variety of STPD instruments is a strength as it allows the PD to be investigated from varying approaches and perspectives.

The Referential Thinking Scale (REF; Lenzenweger, Bennett, \& Lilienfeld, 1997) is a unidimensional questionnaire, featuring 34 items that measures simple and guilty ideas of reference. A referential idea is a thought that is perceived to originate from within the individual. A simple referential idea is when the individual believes that other people are observing something about themselves that they would rather remain private. A guilty referential idea is when the individual feels that they are being accused of some wrongdoing. The authors also note that referential thinking is not exclusive to schizotypal PD, therefore the instrument is designed to measure referential thought in the clinical domain, and be wholly independent of normative referential thought processes such as self-monitoring and self-consciousness. The original paper cites Cronbach's alpha levels to be .83 and a test-retest reliability of .86. Furthermore the original authors found convergent validity for the instrument by demonstrating high REF scores to be associated with increased levels of schizophrenia-related psychological deviance, magical ideation and perceptual aberration. The measure also held weak correlations with unrelated measures of normative self-awareness, suggesting that the REF is measuring a psychologically independent aspect of referential thought processes.

The Schizotypal Personality Questionnaire (SPQ; Raine, 1991) is a 74 item self-report questionnaire that measures all nine schizotypal traits that are laid out in the DSM-III-R. These are: Ideas of reference, excessive social anxiety, odd beliefs, unusual perceptual experiences, odd behaviour, no close friends, odd speech, constricted affect and suspiciousness. Some have questioned the heterogeneous structure of schioztypal PD (Chmielewski \& Watson, 2008). The measure is designed to act as a screening tool for the diagnosis of the disorder, alongside furthering research into the field by gathering data on the individual subscales of the PD. The 
measure produces an overall SPQ score as well as a score for each subscale. Participants respond via a forced-choice “yes/no” paradigm. Cronbach’s alpha level for the total measure was .91, with each subscale varying from .63 (constricted affect) to .81 (odd beliefs). Raine also found a test-retest correlation of .82. The instrument was validated by comparing its scores with the SCID-II omnibus measure of PD. Raine found that of the top $10 \%$ of scorers on the SPQ, fifty-five percent were also diagnosed with schizotypal PD by the SCID-II (suggesting high criterion validity as the bottom 10\% of SPQ scorers received no SCID-II diagnosis). Convergent validity was also supported as each of the nine subscales (including the total score) held significant positive correlations with SCID-II scores (total SPQ score $\mathrm{r}=.68, p<.001$ ).

Raine and Benishay (1995) developed the Schizotypal Personality Questionnaire-Brief (SPQ-B). It was designed to be a shorter version of the SPQ so that it could be used as a screening measure. Featuring only 22 items, it measures three dimensions: interpersonal deficits, cognitive-perceptual deficits and disorganisation (which combine to produce a total measure). The SPQ-B only takes two minutes to complete (lending its usefulness to academics and clinicians prior to a confirmatory interview). The original paper cites a Cronbach's alpha level of .76, with Compton, Chien and Bollini (2007) finding a level of .86 within a psychiatric sample. Compton and colleagues also found the SPQ-B to be positively correlated with the SCID-II STPD subscale (r $=.49, p<.001)$. Much like the SPQ, while it is a very robust measure psychometrically and across different samples (Axelrod, Grilo, Sanislow, \& McGlashan, 2001), it still remains based on the DSM-III-R, though it remained largely unchanged in DSM-IV.

The Structured Interview for Schizotypy (SIS) (Kendler, Lieberman, \& Walsh, 1989) is an interview-based research instrument for assessing symptoms of Schizotypal PD. The interview differed from other interviews at the time of its development in that it includes contextualised assessments of the pathological nature of specific symptoms (e.g. referential ideas) and symptom probes that aim to make faking good appear non-deviant. Based on the DSM-III-R, it features five kinds of items: closed-options (i.e. Likert scales), field-coded questions (i.e. an open ended question is asked and the interviewer codes the answer with a number that lays on a continuum), global symptom scores (measured via a one to seven Likert scale), specific symptom scores (the interviewer rates the responder's severity of behaviours) and global scores on broad categories of behaviours. There are 19 sections to the SIS, measured across 16 dimensions. The interview takes around one hour to complete, and interviewers must be especially trained. The authors found inter-rater reliability to be high for the subscales (.87 \pm .12) except magical thinking (.79 to .67), as assessed across two clinical samples (total $N=58$ ). Discriminant validity was demonstrated, as across three pilot studies, SIS scores discriminated between participants who had schizophrenic relatives and those who did not.

Wisconsin Schizotypy Scales (Winsterstein et al., 2011). The magical ideation, perceptual aberration, revised social anhedonia and physical anhedonia scales each contain 15 items and measure a single dimension. They are designed solely for academic use. The authors found each scale to have high Cronbach's alpha levels (.84 to .88). The scales correlated with the HEXACO-60 (Ashton \& Lee, 2009), measures of curiosity (Kashdan et al., 2009), sensation seeking (Hoyle, Stephenson, Palmgreen, Lorch, \& Donohew, 2002) and hypomania (Eckblad \& Chapman, 1986). These measures were thought to represent the positive and negative dimensions of schizotypy. In agreement with previous studies (Kwapil, Barrantes-Vidal, \& Silvia, 2008), modest correlations were found between the four scales and the aforementioned measures.

The Oxford-Liverpool Inventory of Feelings and Experiences (O-LIFE; Mason, Claridge, \& Jackson, 1995). The O-LIFE views schizotypy to lie on a continuum between normality and abnormality. It was designed to be primarily used within a normal population. It comprises four dimensions: unusual experiences, cognitive disorganisation, introvertive anhedonia and impulsive nonconformity, with each ranging between 24 - 30 items. Cronbach's alpha level for the scales ranged between .77 and .89. The O-LIFE's validity has been supported in a variety of laboratory studies ranging from neurological functioning, performance on reasoning tasks, faceprocessing and childhood abuse (Avons, Nunn, Chan, \& Armstrong, 2003; Sellen, Oaksford, \& Gray, 2005; Mason \& Claridge, 1999; Startup, 1999).

The Five-Factor Measure of Schizotypal Personality Traits (FFM STPT; Edmundson, Lynam, Miller, Gore, \& Widiger, 2011) groups nine scales, constructed as maladaptive variants of FFM general traits, including Social Anxiousness (the STPT variant of FFM N1: Anxiety), Social Discomfort (the STPT variant of FFM N4: Self-consciousness), Social Anhedonia (low E1: Warmth), Social Isolation and Withdrawal (low E2: Gregariousness), Physical Anhedonia (Low FFM E6: Positive emotions), Aberrant Perceptions (O1: Fantasy), Odd and Eccentric (O4: Actions), Aberrant Ideas (O5: Ideas), and Interpersonal Suspiciousness (low FFM A1: Trust). 
Together, these scales are called the Five-Factor Schizotypal Inventory (FFSI). The FFSI-scales showed good psychometric properties, including support for its convergent, divergent and incremental validity beyond already existing measures.

\subsection{Antisocial}

Antisocial PD (APD) continues to be of a popular interest to researchers and clinicians of various fields. Eight measures of APD will be detailed below, however there is some inconsistency in terminology within the domain. For instance psychopathy can be referenced as a specific subtype of APD or as a synonym (Pickersgill, 2010).

The Antisocial Personality Questionnaire (APQ; Blackburn \& Fawcet, 1999) is a 125-item self-report inventory that is designed to measure APD holistically in criminal offender populations. The measure features eight scales: self-control, self-esteem, avoidance, paranoid suspicion, resentment, aggression, deviance and extraversion, with Cronbach's alpha levels ranging from .77 to .87. Validated in both a clinical and normal population, all scales were found to hold concurrent validity with the MCMI alongside predicting the age of an inmate's first criminal offence and the length of detention.

The Psychopathy Checklist (PCL; Hare, 1980) has become the standard measure of psychopathy in clinical environments since it was created. When categorised as a subtype of APD, Hare defines psychopathy to be characterised by callous and unemotional traits. The PCL assesses two factors: the first focusing on the individual's grandiose, callous and manipulative personality, and the second focusing on the individual's deviant and impulsive life history. It has 22 items (each of which represent a facet of either factor) that form the basis of a semi-structured interview. To administer this checklist, interviewers must first take a short course to become accredited. Each item is scored on a range from 0 to 3, where higher scores represent severity. With scores ranging from 0 to 44, scores above 30 indicate a diagnosis of clinical psychopathy. Hare found that the PCL held a Cronbach's alpha level of .90 and interrater reliability levels of .89, demonstrating good psychometric properties for a clinical interview. Hart and Hare (1989) demonstrated discriminant validity as the PCL scores were related to substance abuse.

The Psychopathy Checklist-Revised (PCL-R; Hare et al., 1990) is based on the PCL, however only features 20 items. It remains as a clinical interview that requires specific training to be administered, with scores over 30 indicating the presence of psychopathy. Furthermore, it still assesses the same two factors. The PCL-R removed two items that were found to hold low correlations with the total PCL score, as well as slightly modified the scoring criteria. The PCL-R has been well validated, and has superseded its precursor in popularity. Being validated in five clinical samples $(N=925)$, the average inter-rater reliability and Cronbach's alpha level was .86 and .88 respectively. Salekin, Rogers, and Sewell (2006) found that PCL and PCL-R scores were significant predictors of future violence and aggression. Vitale, Smith, Brinkley and Newman (2002) found convergent validity with Eysenck’s Personality Questionnaire, in particular the psychoticism scale (Eysenck \& Eysenck, 1975). The PCL-R is often favoured over the PCL due to its psychometric refinements. Furthermore, it is worth highlighting that the PCL/PCL-R measures a slightly different construct to the APQ: the APQ measures APD as defined by the DSM-IV, whereas the PCL-R measures psychopathy as a subtype of APD.

Levenson's Self-Report Psychopathy Scale (SRPS; Levenson, Kiehl, \& Fitzpatrick, 1995) is a 26-item selfreport questionnaire that measures primary psychopathy (a synonym for factor 1 of psychopathy as measured by the PCL-R) and secondary psychopathy (a synonym for factor 2). Unlike the PCL-R, the SRPS was designed to be used in a nonclinical population. Brinkley, Schmitt, Smith and Newman (2000) found the measure to have Cronbach alphas of .83 for primary psychopathy, .69 for secondary, and .85 for the total measure. The authors also found the SRPS to positively correlate with the PCL-R and demonstrate similar correlations to measures of substance abuse and criminal versatility which may be evidence of its poor discriminant validity. Akhtar, Ahmetoglu, and Chamorro-Premuzic (2013) demonstrated its predictive validity by using the measure to predict entrepreneurial outcomes, therefore providing support for the SRPS' utility in nonclinical samples.

The Psychopathic Personality Inventory Revised (PPI-R; Lilienfield \& Widows, 2005) is another self-report measure of personality traits associated with psychopathy. Featuring 157 items, the PPI-R contrasts both the PCL-R and SRPS as it measures three dimensions of psychopathy: fearless dominance (traits that reflect social potency, shallow affect and stress immunity), impulsive antisociality (traits that reflect impulsive nonconformity, externalisation of blame and Machiavellian behaviours), and cold heartedness (lack of empathy). The original authors found Cronbach's alpha levels to range from .79 to .92. Uzieblo, Verschuere, Van den Bussche, and 
Crombez, (2010) further found that the measure held convergent and discriminant validity with the SRPS; all three factors of the PPI-R were positively correlated with primary psychopathy, fearless dominance and impulsive anti-sociality correlated with secondary psychopathy. The authors created the PPI-R to challenge the monopoly the PCL-R had within the field and to address a variety of theoretical challenges within the field. The measure was designed to be used within both non- and clinical samples.

The Elemental Psychopathy Assessment (EPA; Lynam et al., 2011) is a 178 self-report measure that features 18 psychopathy subscales. The subscales are grouped into four unidimensional factors that are based on the FFM: antagonism, conscientiousness, extraversion and neuroticism. The authors chose this approach as they argued that psychopathy could be understood if it is related to the basic units of personality. For each of the subscales, Cronbach's alpha levels ranged between .63 and .88. In a clinical sample, the original authors showed that the EPA correlated with three measures of psychopathy, including the PPI-R and SRPS (mean $r=.81$ ). EPA scores were also correlated with externalised behaviours such as alcohol abuse and antisocial behaviour in a prison sample. The benefit of using the EPA over other measures of psychopathy and APD is that its framework of the FFM allows other assessments that are based upon the FFM to be congruent with each other.

The Inventory of Callous-Unemotional Traits (ICU; Frick, 2004). The ICU differentiates itself from psychopathy, as it focuses on an individual's empathy and caring behaviours, particularly in adolescents. Therefore the measure tries to capture behaviour across 24 items to help identify those most at risk. There are four scales; careless, callous, unemotional and uncaring. Participants respond via a 4-point Likert scale. Kimonis et al. (2008a, 2008b) found the total 24 items to hold a Cronbach's alpha of .81, with the subscales ranging tween .53 and .81. They also found the measure to hold concurrent validity as it was found to positively correlate with proactive and reactive aggression, delinquency and sexual offences, while negatively correlating with empathy and positive affect.

The Business-Scan 360 (B-Scan 360; Babiak \& Hare, 2012) has been developed to investigate psychopathic features in business settings. This 360 degree tool is designed for managers, subordinates, and peers to assess corporate psychopathy in others. Initially, the B-Scan consisted of 113 items, to be rated on a 5-point Likert Scale, ranging from 1 (strongly Disagree) to 5 (Strongly Agree). Mahieu and colleagues (2012) collected data in two large independent samples of business personnel who rated their supervisors on the original B-Scan items and on several external variables. They identified a preliminary 20-item B-Scan scale that is consistent with the four PCL-based factors of psychopathy, being Interpersonal (superficial, grandiose, deceitful), Affective (lacks remorse, lacks empathy, doesn't accept responsibility for actions), Lifestyle (impulsive, lacks realistic goals, irresponsible), and Antisocial (poor behavior controls, adolescent antisocial behavior, adult antisocial behavior). Because the B-Scan factors are meant to have utility in an organizational environment, these four factors were relabelled as Manipulative/Unethical, Callous/Insensitive, Unreliable/Unfocused, and Intimidating/Aggressive. In both samples, internal consistencies of the scales and total score were acceptable to excellent, ranging between .70 (Intimidating/Aggressive) to .99 (Callous/Insensitive). Initial data on the external validity seem promising as the psychopathic features measured with the B-Scan seem to be related to deviant behaviors at the workplace, including organizational retaliatory behavior, bullying, and interpersonal deviance (Mahieu et al., 2012).

\subsection{Borderline}

To our knowledge there are seven specific measures of borderline PD (BPD), nearly all adopt a multidimensional approach to measuring BPD. However there is some variation between the number and labels of the dimensions measured.

The Zanarini Rating Scale for Borderline Personality Disorder (ZAN-BPD; Zanarini et al., 2003), features nine items where respondents answer via a 5-point Likert scale. It was found to have reasonably good levels of internal consistency and convergent validity with other BPD measures. The ZAN-BPD defines BPD as consisting of four dimensions: affective, cognitive, impulsive and interpersonal. The scale is designed to be used within a clinical setting to quickly measure changes in symptomatology over time.

The Diagnostic Interview for Borderlines (DIB-R; Zanarini, Gunderson, Frankenburg, \& Chauncey, 1989) is a semi-structured interview that lasts between 50 - 90 minutes. Using 132 items, the DIB-R measures the same four dimensions as the ZAN-BPD but in considerably more depth. The DIB-R is one of the most widely used instruments for BPD diagnoses due to it being: in the public domain, possessing established psychometric qualities such 
as good interrater reliabilities (Kappa levels range between .57 and .73; Zanarini, Frankenbug \& Vujanovic, 2002) and longitudinal predictive validity of remission rates (Zanarini, Frankenburg, Hennen, \& Silk, 2003).

The McLean Screening Instrument for Borderline Personality Disorder (MSI-BPD; Zanarini et al; 2003) is a 10 -item self-report scale that is designed to complement clinical interview instruments as it identifies the potential of a possible diagnosis. Its brevity, test-retest reliability (.72), good sensitivity (correctly identified $81 \%$ of diagnoses) and specificity (correctly identified $85 \%$ of non-diagnoses) make it a useful screener.

The Borderline Personality Disorder Beliefs Scale (BPDBS; Butler, Brown, Beck, \& Grisham; 2002) differs from the aforementioned BPD instruments, as the BPDBS is influenced by cognitive behavioural therapy (Beck \& Freeman, 1990) as it is constructed out of 14 items found on the Personality Belief Scale (PBS; Beck \& Beck, 1991). Butler and colleagues (2002) identified that these 14 items could discriminate between BPD patients and patients with other PDs. Although not widely used, the BPDBS's partnership with cognitive therapy offers a different approach for clinicians and researchers alike.

The Borderline Personality Questionnaire (BPQ; Poreh et al., 2006) is an 80 item self-report scale. Unlike the aforementioned instruments that focus around four dimensions, the BPQ has nine. Although there is some similarity (affective instability, impulsivity and relationships), it introduces dimensions such as intense anger, suicide/self-mutilation and quasi-psychotic states. When compared with the MMPI and the SPQ, it showed significant coefficients of .48 and .45 respectively, suggesting acceptable discriminant validity. Similarly, convergent validity with the MMPI yielded a coefficient of .85 .

The Borderline Evaluation of Severity Over Time (BEST; Pfohl, Blum, St. John, McCormick, Allen, \& Black; 2009) is a 15 item self-report instrument that differs from other measures of BPD as it is focused on how symptomatology changes over time, rather than diagnosing the disorder. The BEST features three subscales each focusing on either: problematic thoughts and emotions that are characteristic of BPD (e.g. suicidal flirtations), problematic behaviours, or the use of positive behaviours. Each item is rated on a 5-point Likert scale. The tool measures respondents' behaviour over the previous week, explaining its utility for therapists and clinicians. The original paper cites test-retest reliabilities ( $\mathrm{r}=.61, p<.001$ ), alongside face validity (due to its focus on the thoughts and feelings of the individual), and concurrent validity (it was shown to correlate significantly with the ZAN-BPD).

Five Factor Borderline Inventory (FFBI; Mullins-Sweatt, Edmundson, Sauer-Zavala, Lynam, Miller, \& Widiger; 2012). This measure is unique in that it builds its structure around the five-factor model of personality, promoting a new multi-dimensional approach of BPD. The authors argue that by viewing BPD as comprising a constellation of maladaptive traits rather than a homogenous category, the full range of the disorder can be assessed. It assesses eight scales, each with 10 items. Items vary from five factor-based traits such as rashness, distrustfulness, and manipulativeness, to more traditional behavioural and affective dysregulation. The original paper cites internal consistency levels no less than .77 and good convergent validities with the PDQ, PAI and SNAP. It was also shown to hold incremental validity at predicting BPD over the NEO PI-R and the BPD scale of the PAI.

\subsection{Histrionic}

The Five-Factor Measure of Histrionic Traits (FFM-HIS; Tomiatti, Gore, Lynam, Miller, \& Widiger, 2012). Parallel to maladaptive variants of FFM schizotypal and borderline traits, 13 Five Factor Histrionic trait scales were constructed as maladaptive variants of FFM general traits, including Neediness for Attention and Rapidly Shifting Emotions, Intimacy Seeking, Attention Seeking, Social Butterfly, Flirtatiousness, Melodramatic-Emotionality, Romantic Fantasies, Touchy Feely Suggestibility, Vanity, Disorderliness, and Impressionistic Thinking. Tomiatti and colleagues (2012) reported good psychometric qualities, adequate convergent validity for 11 out of the 13 FFHI scales and incremental validity over their respective NEO-PI-R facet scales for 12 out of 13 scales in accounting for PDQ-4 histrionic variance.

\subsection{Narcissistic}

Narcissistic PD (NPD) has generated a lot of interest in the past 40 years, with various instruments dedicated to identify and diagnose this PD. There are many different approaches to NPD, debating whether it is multidimensional and its place within the clinical sphere.

Murray's Narcissism Scale (1938) is a 20-item self-report scale that measures narcissism in terms of overt, 
grandiose behaviour and covert feelings of insecurity. Despite the age of the instrument, its theoretical underpinnings are convergent with recent literature. Hendin and Cheek (1997) found the measure to have a Cronbach's alpha of .76 and found 10 of the items from Murray's scale to significantly correlate with MMPI's narcissism scale, demonstrating concurrent validity. They constructed a Hypersensitive Narcissism Scale (HSNS) that measures the covert aspect of narcissism. This was shown to have a Cronbach's alpha of .82 and correlated with the five-factor model of personality, MMPI and the exploitativeness/entitlement dimension of the NPI-40. Arble (2008) further found this measure to hold negative correlations with self-esteem and positive correlations with self-reported measures of shame, masochism, social inhibition, social incompetence and egocentricity.

The Narcissistic Personality Inventory (NPI; Raskin \& Hall, 1979) has received a considerable amount of attention since its first conception. Based on the DSM-III definition, it features 54 items that measure a general construct of trait narcissism (that is narcissism within nonclinical populations). Raskin and Hall (1981) reported that over an eight-week period the instrument's test-retest reliability was .72. In contrast to Raskin and Hall's original conception of a single construct, a factor analysis revealed four salient dimensions: leadership/authority, superiority/arrogance, self-absorption/self-admiration and exploitativeness/entitlement (Emmons, 1984). These four factors accounted for $72 \%$ of all variance with respective Cronbach alpha's of .86, .74, .79, .69, and .69 for the total scale. Emmons (1984) also found the NPI to correlate with normal personality dimensions and peer ratings of narcissism, providing support for the validity of the construct. Lastly, Priftera and Ryan (1984) found the NPI to be strongly correlated with the MCMI narcissism scale within a clinical sample.

Raskin and Terry (1988) further developed the NPI, producing the NPI-40, which has become the most popular measure to assess NPD. The NPI-40 features just 40 items with a Guttman alpha of internal consistency statistic of .83. Most interesting about this version of the NPI is that seven dimensions were also identified: authority, exhibitionism, superiority, vanity, exploitativeness, entitlement, and self-sufficiency-all of which were found to have internal consistency levels no lower than .50. The total scale and its dimensions were found to correlate with various trait rankings on self-confidence, physical attractiveness, pleasure seeking and assertiveness as measured by other instruments included in the Institute of Personality Assessment and Research (IPAR) battery.

Ames, Rose and Anderson (2006) reduced the NPI-40 to a 16-item, uni-dimensional measure. The NPI-16 incorporates the seven factors found within the NPI-40, however it produces a single score that simply represents how narcissistic the individual is. The NPI-16 was found to have a Cronbach's alpha level of .72, which is satisfactory as the authors found the NPI-40 to have a level of .84. Both the NPI-40 and NPI-16 correlated with self-ratings of attractiveness, competence, and big five measures, suggesting evidence of predictive validity.

Margolis-Thomas Measure of Narcissism (M-T; Margolis \& Thomas, 1980). The M-T, an unpublished master's thesis, differs from the NPI as it is able to make clinical diagnoses. The scale features 60 items, and measures the six dimensions of NPD defined by the DSM-III. Each item is a paired statement, with one being narcissistic and the other not, and respondents choose the statement they believe is most true to themselves. The original authors cite an internal consistency coefficient of .84, with the measure successfully differentiating between adolescents with and without NPD, suggesting concurrent validity. Mullins and Kopelman (1988) created a short version that consisted of only 24 paired samples, as they wanted a smaller, more efficient battery. This scale had an internal consistency level of .69. This short version was inversely related to life, self-, family and job satisfaction demonstrating evidence of predictive validity.

The Pathological Narcissism Inventory (PNI; Pincus, Ansell, Pimentel, Cain, Wright, \& Levy, 2009). The PNI differs from various other narcissism measures as it aims to distinguish between pathological/clinical and normal narcissism. Comprising of 52 items, it assesses two overarching dimensions: narcissistic grandiosity and narcissistic vulnerability. Narcissistic grandiosity features four pathological facets that are not dissimilar to those found in the NPI-40: entitlement rage, exploitativeness, grandiose fantasy, and self-sacrificing self-enhancement. Narcissistic vulnerability comprises of three facets: contingent self-esteem, hiding the self, and devaluing. Therefore the PNI is similar to Murray's original conception of narcissism that consists of overt and covert behaviours. The PNI was found to have a Cronbach's Alpha of .95, with all the facets scoring between .75 and .93. Concurrent validity was found as PNI scores held significant correlations with NPI and HSNS scores (this is true for both total and facet scores). PNI scores were also found to predict empathy, aggression and low moral values, as well as psychiatric variables such as number of suicide attempts, no-shows to therapy sessions, and whether psychiatric medication is being taken.

Five Factor Narcissism Inventory (FFNI; Glover et al., 2012). Like its sister inventories, the FFNI groups 15 
narcissism trait scales that are constructed as maladaptive and narcissistic variants of FFM facets, including Reactive Anger, Shame, Indifference, Need for Admiration, Exhibitionism, Thrill-Seeking (also represented in the EPA; Lynam et al., 2011), Authoritativeness, Grandiose Fantasies, Cynicism/Distrust (also represented in the EPA; Lynam et al., 2011), Manipulativeness, Exploitativeness, Entitlement, Arrogance, Lack of Empathy, and Acclaim-Seeking. Good to excellent internal consistencies were reported, including adequate convergent validity for 14 out of 15 FFNI scales. It was concluded that the 15 different scales provided a comprehensive and multifaceted description of narcissistic pathology.

There are also other less well known measures of NPD (Ashby, Lee, \& Duke, 1979; Richman \& Flahery, 1990).

\subsection{Avoidant}

No specific measure of avoidant personality could be found, except for the Five-Factor Avoidant Assessment (FFAvA; Lynam, Loehr, Miller, \& Widiger, 2012), proposing 10 maladaptive avoidant variants of FFM traits, including scales assessing Evaluation Apprehension, Despair, Mortified, Overcome, Social Dread, Shrinking, Risk Averse, Joyless, Rigidity, and Timorous. Initial validation results are promising, showing homogenous and reliable scales, that are strongly related to their respective NEO-PI-R facets, and with all FFAvA scales, except Timorous, showing expected relationships with AVD measures enclosed in comprehensive PD inventories.

\subsection{Dependent}

The DSM-5 characterises DPD as displaying maladaptive clinging behaviour towards others for care, advice and support. Our review identified four instruments that specifically measured DPD.

The Minnesota Multiphasic Personality Inventory-2 Social Introversion Subscales (MMPI-2 Si1, 2, 3; Ben-Porath, Hostetler, Butcher, \& Graham, 1989). The instrument consists of 38 items and is based on the subscales of MMPI-2. Using item-level factor-analysis, Ben-Porath and colleagues produced three exclusive subscales that are designed to collectively measure DPD, in particular the avoidance of being alone. The three scales, Shyness/Self Consciousness, Social Avoidance, and Self/Other Alienation, were found to hold acceptable internal consistency coefficients (ranging between .75 and .82). The authors found that two subscales predicted $80 \%$ of the variance in a study on social introversion. Further ad hoc validity for the role of shyness comes from Lorant, Henderson, and Zimbardo (2000) who found that in a clinical sample $(N=107), 60$ participants that were found to be shy, also had a personality disorder, with DPD being the most common. Unfortunately there have not been many studies to further validate the three subscales. It could even be criticised in that the scales are not directly measuring DPD—rather a facet, or another comorbid construct altogether.

The Dependent Personality Questionnaire (DPQ; Tyrer, Morgan, \& Cicchetti, 2004) is an eight item self-report questionnaire. The instrument is intended to be used as a screening tool to identify patients that potentially have DPD. Participants rate themselves using a 4-point Likert scale that ranges from 0 to 3 . Although the original authors do not cite any statistics on the instrument's reliability, they demonstrate that the DPQ holds good diagnostic validity. The DPQ held an overall diagnostic accuracy of $87.5 \%$ in psychiatric patients diagnosed with DPD according to the ICD-10 version of the Personality Assessment Schedule (Tyrer, 2000). The DPQ's diagnostic sensitivity, specificity, predicted positive and negative accuracies were all 87.5\%. Compared to matched controls, patients diagnosed with the disorder had a mean score of 13 (controls comparably scored a mean of 7).

The Dependent Personality Inventory (DPI; Huber, 2005). The DPI is a 55-item questionnaire that measures seven independent factors representing various symptoms of DPD as defined by the DSM-IV, including: difficulty making decisions, assuming responsibility, difficulty expressing disagreement, difficulty initiating projects, seeking support from others and feeling helpless and alone. The original paper found the DPI to have a high internal consistency with a Cronbach's alpha of .90.

The Five-Factor Measure of Dependent Traits (FFM DPT; Gore et al., 2012). Gore and colleagues created 12 scales to assess FFM dependent traits, including Separation Insecurity, Pessimism, Shamefulness, Helplessness, Intimacy Needs, Unassertiveness, Gullibility, Selflessness, Subservience, Self-effacing, Ineptitude, and Negligence. Internal consistencies of the scales were good, and scales correlated with their NEO-PI-R equivalents, also demonstrating discriminant validity towards different NEO-traits, and incremental validity beyond their corresponding NEO PI-R facets to explain variance in the SNAP DPD scale. 
There are also some other measures of DPD (Hirschfeld, Klerman, Gouch et al., 1977; Bornstein, Geiselman, Eisenhart, \& Languirand, 2002; Bornstein, Languirand, Geisleman et al., 2003).

\subsection{Obsessive-Compulsive}

Obsessive-compulsive PD (OCPD) is rather similar to the Axis 1 obsessive-compulsive disorder (OCD), and therefore they are often confused. Indeed it has been suggested that the evidence for the construct validity of these two scales was mixed (Phillips et al., 2010). However, where OCD can be defined as a mental disorder characterized by ego-dystonic, intrusive and time-consuming obsessions and compulsions, OCPD rather reflects an ego-syntonic personality style including stable traits such as perfectionism and rigidity. Assessing these disorders is difficult due to their comorbidity with (each other and) other disorders as well as their heterogeneity.

The Five Factor Obsessive-Compulsive Inventory (FFOCI; Samuel, Riddell, Lynam, Miller, \& Widiger, 2012) is a self-report measure that maps OCPD onto the FFM. The 12 dimensions of the instrument each represent a maladaptive, lower-order version of a big five trait. The scale's Cronbach's alpha levels ranged between .77 and .87. The scales were shown to hold convergent validity with the MCMI-III $(\mathrm{r}=.58, p<.01)$, PDQ-4 $(\mathrm{r}=.50$, $p<.01)$ and the SNAP-2 $(\mathrm{r}=.66, p<.01)$. The instrument was also found to hold incremental validity over the MCMI-III.

\section{Discussion}

This paper has been a PD assessment "housekeeping and auditing” exercise, targeting comprehensiveness rather than reflecting usage frequency or the publication track-record of instruments. Such criteria probably more reflect whether a measure has been included in one of the four major longitudinal studies on PDs resulting in an increased number of publications, instead of reflecting their quality status. We made the choice to go back as far as DSM-III covering old and new measures. We also did not do a "quality control" in terms of journal ratings as these vary over time and have been criticised.

This review has made a number of things clear: (a) there are multiple options to assess PDs, both comprehensively and specifically, (b) objectives of users may largely vary, going from general screening towards differentiated (clinical) diagnostics, (c) methods vary in terms of in-depth assessment and necessary time, with structured interviews generally preferred for clinical assessment over self-report inventories, (d) there exist a number of "fore wash" assessment methods, that may be followed by more in-depth assessment when appropriate, (e) also the contexts of the assessment may vary, ranging from clinical to more personal developmental and occupational related questions, and finally (f) methods may differ in terms of whether they assess primarily pathological trait variance or also tap into general traits.

To facilitate choosing among measures, a decision tree was developed distinguishing three major entries, i.e. research, clinical assessment and assessment with a developmental purpose (Figure 1). Researchers can choose between categorically-based versus more dimensionally-based PD measures usually relying on individuals' self-reports. A similar dichotomy is available for clinical diagnostics and decision making, with the same dimensional measures available like for research purposes. Categorically-based clinical assessment may first involve a pre-screening followed by more specific PD assessment focussing on single PDs. Our review has made clear that there are various options for the majority of the PDs. A broader clinical assessment procedure may also include a comprehensive PD assessment, usually done via structured interviews, assessing both nature and severity of personality pathology in terms of DSM-5 categorical constructs. Finally, an increasing number of psychologists are interested to use personality pathology assessment instruments and methods to identify an individual's personal and professional needs, in order to help develop and mould the sharp sides of their personalities. These are often related to subclinical forms of personality pathology, also called aberrant personality tendencies (Wille et al., 2013; De Fruyt et al., 2013ab). Given the idea of a spectrum or continuum between dimensions of general and maladaptive personality traits (De Bolle et al., 2012) and that the US Legislation (Americans with Disabilities Act, ADA, 1990) prohibits that clinical measures are used in personnel selection and development assessments, FFM general trait based measures of personality dysfunction seem to be most useful. In addition, also a number of DSM-IV based personality measures have been developed to understand personality functioning at work, contextualizing the item content and/or instructions with a work-frame. Also for these purposes, different options are available and increasingly used.

The purpose of the present review was not only to list the available PD measures, but also to illustrate the 


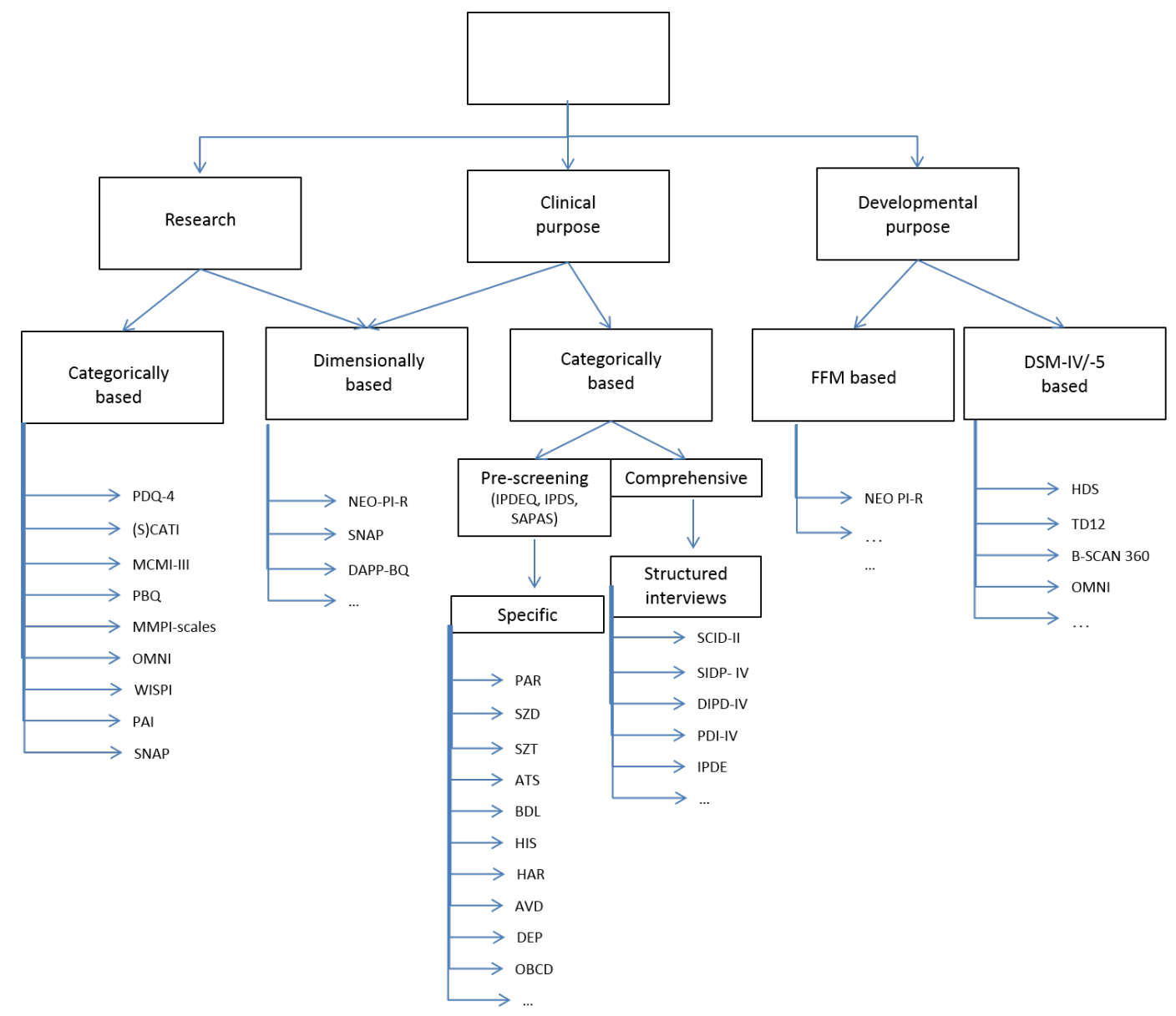

Figure 1. Personality pathology assessment decision tree.

increased attention and use of such assessment devices for a broader range of purposes including clinical and non-clinical assessment and research. This expanded scope is a direct consequence of advances in the conceptualization of PDs from distinct categorical entities to the consideration of personality pathology dimensions that are more quantitatively than qualitatively different from normal trait variation. Despite the many suggestions to replace the categorical PDs by a dimensional system including more specific traits, DSM- 5 continues the categorical conceptualisation of PDs making our review of assessment methods still timely. We hope that professionals and researchers will find our review helpful in choosing an appropriate assessment method for their purposes, but will consider at the same time also the trait based system of personality pathology described in DSM-5 Section 3.

\section{References}

Abdin, E., Koh, K. G., Subramaniam, M., Guo, M. E., Leo, T., Teo, C., Tan, E. E., \& Chong, S. A. (2011). Validity of the Personality Diagnostic Questionnaire-4 (PDQ-4+) among Mentally Ill Prison Inmates in Singapore. Journal of Personality Disorders, 25, 834-841. http://dx.doi.org/10.1521/pedi.2011.25.6.834

Akhtar, R., Ahmetoglu, G., \& Chamorro-Premuzic, T. (2013). Greed Is Good? Assessing the Relationship between Entrepreneurship and Subclinical Psychopathy. Personality and Individual Differences, 54, 420-425. http://dx.doi.org/10.1016/j.paid.2012.10.013

American Psychiatric Association (2000). Diagnostic and Statistical Manual of Mental Disorders (4th., text revision ed.). Washington, DC: American Psychiatric Association.

American Psychiatric Association (2013). Diagnostic and Statistical Manual of Mental Disorders (5th ed.). Arlington, VA: American Psychiatric Publishing. 
Ames, D. R., Rose, P., \& Anderson, C. P. (2006). The NPI-16 as a Short Measure of Narcissism. Journal of Research in Personality, 40, 440-450. http://dx.doi.org/10.1016/j.jrp.2005.03.002

Arble, E. P. (2008). Evaluating the Psychometric Properties of the Hypersensitive Narcissism Scale: Implications for the Distinction of Covert and Overt Narcissism. Masters Thesis and Doctoral Dissertations, Paper 236.

Ashby, H. U., Lee, R. R., \& Duke, E. H. (1979). A Narcissistic Personality Disorder MMPI Scale. Paper presented at the 87th Annual Convention of the American Psychological Association, New York, NY.

Ashton, M. C., \& Lee, K. (2009). The HEXACO-60: A Short Measure of the Major Dimensions of Personality. Journal of Personality Assessment, 91, 340-345. http://dx.doi.org/10.1080/00223890902935878

Avons, S. E., Nunn, J. A., Chan, L., \& Armstrong, H. (2003). Executive Function Assessed by Memory Updating and Random Generation in Schizotypal Individuals. Psychiatry Research, 120, 145-154. http://dx.doi.org/10.1016/S0165-1781(03)00174-4

Axelrod, S. R., Grilo, C. M., Sanislow, C., \& McGlashan, T. H. (2001). Schizotypal Personality Questionnaire-Brief: Factor Structure and Convergent Validity in Inpatient Adolescents. Journal of Personality Disorders, 15, 168-179. http://dx.doi.org/10.1521/pedi.15.2.168.19219

Babiak, P., \& Hare, R. D. (2012). The B-Scan 360 Manual. Manuscript in Preparation.

Bagby, R. (2013). Introduction to Special Issue on the Personality Inventory for DSM-5 (PID-5). Assessment, 20, $267-268$. http://dx.doi.org/10.1177/1073191113491643

Bastiaansen, L., Rossi, G., \& De Fruyt, F. (2012). Comparing a Set of five FFM Personality Disorder Counts. European Journal of Personality, 27, 377-388. http://dx.doi.org/10.1002/per.1859

Beck, A. T., \& Beck, J. S. (1991). The Personality Belief Questionnaire. Unpublished Assessment Instrument. Bala Cynwyd, PA: The Beck Institute for Cognitive Therapy and Research.

Beck, A. T., \& Freeman, A. (1990). Cognitive Therapy of Personality Disorders. New York: Guilford.

Beck, A. T., Butler, A. C., Brown, G. K., Dahlsgaard, K. K., Newman, C. F., \& Beck, J. S. (2001). Dysfunctional Beliefs Discriminate Personality Disorders. Behaviour Research and Therapy, 39, 1213-1225. http://dx.doi.org/10.1016/S0005-7967(00)00099-1

Benjamin, L. S. (1996). Interpersonal Diagnosis and Treatment of Personality Disorders (2nd ed.). New York: Guilford.

Ben-Porath, Y., Hostetler, K., Butcher, J., \& Graham, J. (1989). MMPI-2 Si1-3: Minnesota Multiphasic Personality Inventory Social Introversion Subscales 1-3. In J. R. Graham (Ed.), MMPI-2: Assessing Personality and Psychopathology (p. 130). New York: Oxford University Press, Inc.

Bhar, S. S., Beck, A. T., \& Butler, A. C. (2011). Beliefs and Personality Disorders. Journal of Clinical Psychology, 68, 88100. http://dx.doi.org/10.1002/jclp.20856

Blackburn, R., \& Fawcett, D. J. (1999). The Antisocial Personality Questionnaire: An Inventory for Assessing Deviant Traits in Offender Populations. European Journal of Psychological Assessment, 15, 14-24.

http://dx.doi.org/10.1027//1015-5759.15.1.14

Boone, D. (1998). Internal Consistency Reliability of the Personality Assessment Inventory with Psychiatric Inpatients. Journal of Clinical Psychology, 54, 839-843. http://dx.doi.org/10.1002/(SICI)1097-4679(199810)54:6<839::AID-JCLP12>3.0.CO;2-M

Bornstein, R. F., Geiselman, K. J., Eisenhart, E. A., \& Languirand, M. A. (2002). Construct Validity of the Relationship Profile Test: Links with Attachment, Identity, Relatedness, and Affect. Assessment, 9, 373-380.

http://dx.doi.org/10.1177/1073191102238195

Bornstein, R. F., Languirand, M. A., Geiselman, K. J., Creighton, J. A., West, M. A., Gallagher, H. A., \& Eisenhart, E. A. (2003). Construct Validity of the Relationship Profile Test: A Self-Report Measure of Dependency-Detachment. Journal of Personality Assessment, 80, 64-74. http://dx.doi.org/10.1207/S15327752JPA8001_15

Brinkley, C. A., Schmitt, W. A., Smith, S. S., \& Newman, J. P. (2000). Construct Validation of a Self-Report Psychopathy Scale: Does Levenson's SRPS Measure the Same Construct as Hare's PCL-R? Personality and Individual Differences, 31, 1021-1038. http://dx.doi.org/10.1016/S0191-8869(00)00178-1

Butler, A. C., Beck, A. T., \& Cohen, L. H. (2007). The Personality Belief Questionnaire-Short Form: Development and Preliminary Findings. Cognitive Therapy and Research, 31, 357-370. http://dx.doi.org/10.1007/s10608-006-9041-x

Butler, A. C., Brown, G. K., Beck, A. T., \& Grisham, J. R. (2002). Assessment of Dysfunctional Beliefs in Borderline Personality Disorder. Behaviour, Research and Therapy, 40, 1231-1234. http://dx.doi.org/10.1016/S0005-7967(02)00031-1

Chmielewski, M., \& Watson, D. (2008). Heterogeneous Structure of Schizotypal Personality Disorder. Journal of Abnormal Psychology, 117, 364-376. http://dx.doi.org/10.1037/0021-843X.117.2.364

Chmielewski, M., \& Watson, D. (2009). What Is Being Assessed and Why It Matters: The Impact of Transient Error on Trait Research. Journal of Personality and Social Psychology, 97, 186-202. http://dx.doi.org/10.1037/a0015618 
Clark, L. A. (1993). Schedule for Nonadaptive and Adaptive Personality (SNAP). Manual for Administration, Scoring, and Interpretation. Minneapolis, MN: University of Minnesota Press.

Clark, L. A. (2007). Assessment and Diagnosis of Personality Disorder: Perennial Issues and an Emerging Reconceptualization. Annual Review of Psychology, 58, 227-257. http://dx.doi.org/10.1146/annurev.psych.57.102904.190200

Clark, L. A., \& Harrison, J. A. (2001). Assessment Instruments. In W. J. Livesley (Ed.), Handbook of Personality Disorders: Theory, Research, and Treatment (p. 277-306). New York: Guilford.

Compton, M. T., Chien, V. H., \& Bollini, A. (2007). Psychometric Properties of the Brief Version of the Schizotypal Personality Questionnaire in Relatives with Schizophrenia-Spectrum Disorders and Non-Psychotic Control. Schizophrenia Research, 91, 122-131. http://dx.doi.org/10.1016/j.schres.2006.12.005

Connan, F., Dhokia, R., Haslam, M., Mordant, N., Morgan, G., Pandya, C., \& Waller, G. (2009). Personality Disorder Cognitions in the Eating Disorders. Behaviour Research and Therapy, 47, 77-82. http://dx.doi.org/10.1016/j.brat.2008.10.010

Coolidge, F. L. (1984). Coolidge Axis II Inventory. U.S. Copyright TXU 182-026, Washington, DC.

Coolidge, F. L. (2001). Personal Communication. Questionnaire and Scoring Key for the Short Coolidge Axis-II Inventory. (Provided by the Author)

Coolidge, F. L., \& Merwin, M. M. (1992). Reliability and Validity of the Coolidge Axis II Inventory: A New Inventory for the Assessment of Personality Disorders. Journal of Personality Assessment, 59, 223-238.

http://dx.doi.org/10.1207/s15327752jpa5902 1

Damen, K. F., De Jong, C. A., \& Van der Kroft, P. J. (2004). Interrater Reliability of the Structured Interview for DSM-IV Personality in an Opioid-Dependent Patient Sample. European Addiction Research, 3, 99-104. http://dx.doi.org/10.1159/000077697

De Bolle, M., Beyers, W., De Clercq, B., \& De Fruyt, F (2012). General Personality and Psychopathology in Referred and Nonreferred Children and Adolescents: An Investigation of Continuity, Pathoplasty, and Complication Models. Journal of Abnormal Psychology, 121, 958-970. http://dx.doi.org/10.1037/a0027742

De Fruyt, F., De Clercq, B. J., Miller, J. D., Rolland, J.-P., Jung, S. C, Taris, R., Furnham, A., \& Van Hiel, A. (2009). Assessing Personality at Risk in Personnel Selection and Development. European Journal of Personality, 23, 51-69. http://dx.doi.org/10.1002/per.703

De Fruyt, F., De Clercq, B., De Bolle, M., Wille, B., Markon, K., \& Krueger, R. F. (2013a). Positioning a Maladaptive Personality Trait Model for DSM-5 in a Five-Factor Framework in a University Student Sample. Assessment, 20, $295-307$. http://dx.doi.org/10.1177/1073191113475808

De Fruyt, F., Wille, B., \& Furnham, A. (2013b). Assessing Aberrant Personality in Managerial Coaching: Measurement Issues and Prevalence Rates across Employment Sectors. European Journal of Personality, 27, 555-564. http://dx.doi.org/10.1002/per.1911

Dotlich, D., \& Cairo, P (2003). Why CEOs Fail. New York: Jossey Bass.

Eckblad, M., \& Chapman, L. (1986). Development and Validation of a Scale for Hypomanic Personality. Journal of Abnormal Psychology, 95, 214-222. http://dx.doi.org/10.1037/0021-843X.95.3.214

Edmundson, M., Lynam, D. R., Miller, J. D., Gore, W. L., \& Widiger, T. A. (2011). A Five-Factor Measure of Schizotypal Personality Traits. Assessment, 18, 321-334. http://dx.doi.org/10.1177/1073191111408228

Emmons, R. A. (1984). Factor Analysis and Construct Validity of the Narcissistic Personality Inventory. Journal of Personality Assessment, 48, 291-300. http://dx.doi.org/10.1207/s15327752jpa4803_11

Eysenck, H. J., \& Eysenck, S. B. G. (1975). Manual of the Eysenck Personality Questionnaire. London: Hodder and Stoughton.

First, M. B., Gibbon, M., Spitzer, R. L., Williams, J. B. W., \& Benjamin, L. S. (1997). Structured Clinical Interview for DSM-IV Axis II Personality Disorders (SCID-II). Washington, DC: American Psychiatric Press, Inc.

First, M. B., Spitzer, R. L., Gibbion, M., Williams, J. B. W., Davies, M., Borus, J., Howes, M. J., Kane, J., Pope, H. G., \& Rounsaville, B. (1995). The Structure Clinical Interview for DSM-III-R Personaliy Disorders (SCID-II). Part II: Multisite Test-Retest Reliability Study. Journal of Personality Disorders, 9, 92-104. http://dx.doi.org/10.1521/pedi.1995.9.2.92

Fountoulakis, K. N.,Oacovides, A., Oiannidou, C., Bascialla, F., Nimatoudis, I., Kaprinis, G., Janca, A., \& Dahl, A. (2002). Reliability and Cultural Applicability of the Greek Version of the International Personality Disorders Examination. BMC Psychiatry, 2, 6. http://dx.doi.org/10.1186/1471-244X-2-6

Frick, P. J. (2004). The Inventory of Callous-Unemotional Traits. Unpublished Rating Scale.

Friedman, J. N. W., Oltmanns, T. F., \& Turkheimer, E. (2007). Interpersonal Perception and Personality Disorders. Journal of Research in Personality, 41, 667-688. http://dx.doi.org/10.1016/j.jrp.2006.07.004

Furnham, A., \& Taylor, J. (2004). The Dark Side of Behaviour at Work: Understanding and Avoiding Employees Leaving, Thieving and Deceiving. Hampshire: Palgrave MacMillan. http://dx.doi.org/10.1057/9780230510104 
Furnham, A., Trickey, G., \& Hyde, G. (2012). Bright Aspects to Dark Side Traits: Dark Side Traits Associated with Work Success. Personality and Individual Differences, 52, 908-913. http://dx.doi.org/10.1016/j.paid.2012.01.025

Gebauer, J. E., Sedihides, C., Verplanken, B., \& Maio, G. R. (2012) Communal Narcissism. Journal of Personality and Social Psychology, 103, 854-878. http://dx.doi.org/10.1037/a0029629

Gibbons, M., Spitzer, R. L., Williams, J. B. B., \& Benjamin, L. (1997). Structured Clinical Interview for DSM-IV Axis II Personality Disorders. Washington, DC: APA.

Glover, N., Miller, J. D., Lynam, D. R., Crego, C., \& Widiger, T. A. (2012). The Five-Factor Narcissism Inventory: A Five-Factor Measure of Narcissistic Personality Traits. Journal of Personality Assessment, 94, 500-512. http://dx.doi.org/10.1080/00223891.2012.670680

Gore, W. L., Presnall, J. R., Miller, J. D., Lynam, D. R., \& Widiger, T. A. (2012). A Five-Factor of Dependent Personality Traits. Journal of Personality Assessment, 94, 488-499. http://dx.doi.org/10.1080/00223891.2012.670681

Gustavsson, A., Svensson, M., Jacobi, F., Allgulander, C., Alonso, J., Beghi, E. et al. on behalf of the CDBE Study (2012). Corrigendum to "Cost of Disorders of the Brain in Europe 2010" [Eur. Neuropsychopharmacol. 21 (2011) 718-779]. European Neuropsychopharmacology, 22, 237-238. http://dx.doi.org/10.1016/j.euroneuro.2012.01.001

Hare, R. D. (1980). A Research Scale for the Assessment of Psychopathy in Criminal Populations. Personality and Individual Differences, 1, 111-119. http://dx.doi.org/10.1016/0191-8869(80)90028-8

Hare, R. D., Harpur, T. J., Hakstian, A. R., Forth, A. E., Hart, S. D., \& Newman, J. P. (1990). The Revised Psychopathy Checklist: Reliability, and Factor Structure. Psychological Assessment: A Journal of Consulting and Clinical Psychology, 2, 338-341. http://dx.doi.org/10.1037/1040-3590.2.3.338

Hart, S. D., \& Hare, R. (1989). Discriminant Validity of the Psychopathy Checklist in a Forensic Psychiatric Population. Journal of Consulting and Clinical Psychology, 82, 211-218. http://dx.doi.org/10.1037/1040-3590.1.3.211

Hendin, H. M., \& Cheek, J. M. (1997). Assessing Hypersensitive Narcissism: A Re-Examination of Murray’s Narcissism Scale. Journal of Research in Personality, 31, 588-599. http://dx.doi.org/10.1006/jrpe.1997.2204

Hesse, M., \& Moran, P. (2010). Screening for PD with the Standardised Assessment of Personality: Abbreviated Scale (SAPAS): Further Evidence of Concurrent Validity. BMC Psychiatry, 10, 10. http://dx.doi.org/10.1186/1471-244X-10-10

Hirschfeld, R. M. A., Klerman, G. L., Gouch, H. G., Barrett, J., Korchin, S. J., \& Chodoff, P. (1977). A Measure of Interpersonal Dependency. Journal of Personality Assessment, 41, 610-618. http://dx.doi.org/10.1207/s15327752jpa4106_6

Hogan, R., \& Hogan, J. (1992). Hogan Personality Inventory Manual (2nd ed.). Tulsa, OK: Hogan Assessment Systems.

Hogan, R., \& Hogan, J. (1997). Hogan Development Survey Manual. Tulsa, OK: Hogan Assessment Systems.

Hoyle, R. H., Stephenson, M. T., Palmgreen, P., Lorch, E. P., \& Donohew, R. L. (2002). Reliability and Validity of a Brief Measure of Sensation Seeking. Personality and Individual Differences, 32, 401-414. http://dx.doi.org/10.1016/S0191-8869(01)00032-0

Huber, N. M. (2005). Dependent Personality Inventory (DPI): A Scale to Assess Dependent Personality Subtypes Based on DSM-IV-TR Criteria. Unpublished Master's Thesis, Cleveland, OH: Cleveland State University.

Hurt, S. W., Hyler, S. E., Frances, A., Clarkin, J. F., \& Brent, R. (1984). Assessing Borderline Personality Disorder with a Self-Report, Clinical Interview or Semi-Structured Interview. American Journal of Psychiatry, 30, 145-153.

Hyler, S. E. (1994). Personality Diagnostic Questionnaire-4 (PDQ-4). New York: New York State Psychiatric Institute.

Hyler, S. E., \& Lyons, M. (1988). Factor Analysis of the DSM-III Personality Disorder Clusters: A Replication. Comprehensive Psychiatry, 29, 304-308. http://dx.doi.org/10.1016/0010-440X(88)90053-3

Hyler, S. E., \& Rieder, R. A. (1987). PDQ-R: Personality Disorder Questionnaire-Revised. New York: New York State Psychiatric Institute.

Hyler, S. E., Rieder, R. A., Williams, J. B. W., Spitzer, R. L., Hendler, J., \& Lyons, M. (1988). The Personality Diagnostic Questionnaire: Development and Preliminary Results. Journal of Personality Disorders, 2, 229-237. http://dx.doi.org/10.1521/pedi.1988.2.3.229

Hyler, S. E., Skodol, A. E., Kellman, H. D., Oldham, J. M., \& Rosnick, L. (1990). Validity of the Personality Diagnostic Questionnaire-Revised: Comparison with Two Structured Interviews. American Journal of Psychiatry, 147, 1043-1048.

Hyler, S. E., Skodol, A. E., Oldham, J. M., Kellman, H. D., \& Doidge, N. (1992). Validity of the Personality Diagnostic Questionnaire-Revised: A Replication in an Outpatient Sample. Comprehensive Psychiatry, 33, 73-77. http://dx.doi.org/10.1016/0010-440X(92)90001-7

Jane, J. S., Pagan, J. L., Turkheimer, E., Fiedler, E. R., \& Oltmanns, T. F. (2006). The Interrater Reliability of the Structured Interview for DSM-IV Personality. Comprehensive Psychiatry, 47, 368-375. http://dx.doi.org/10.1016/j.comppsych.2006.01.009

Jones, S. H., Burrell-Hodgson, G., \& Tate, G. (2007). Relationships between the Personality Beliefs Questionnaire and 
Self-Rated Personality Disorders. British Journal of Clinical Psychology, 46, 247-251. http://dx.doi.org/10.1348/014466506X164791

Kashdan, T. B., Gallagher, M. W., Silvia, P. J., Winterstein, B. P., Breen, W. E., Terhar, D. et al. (2009). The Curiosity and Exploration Inventory-II: Development, Factor Structure, and Psychometrics. Journal of Research in Personality, 43, 987-998. http://dx.doi.org/10.1016/j.jrp.2009.04.011

Kendler, K. S., Lieberman, J. A., \& Walsh, D. (1989). The Structure Interview for Schizotypy (SIS): A Preliminary Report. Schizophrenia Bulletin, 15, 559-571. http://dx.doi.org/10.1093/schbul/15.4.559

Kimonis, E. R., Frick, P. J., Munoz, L. C., \& Aucoin, K. J. (2008a). Callous-Unemotional Traits and the Emotional Processing of Distress Cues in Detained Boys: Testing the Moderating Role of Aggression, Exposure to Community Violence, and Histories of Abuse. Development and Psychopathology, 20, 569-589. http://dx.doi.org/10.1017/S095457940800028X

Kimonis, E. R., Frick, P. J., Skeem, J. L., Marsee, M. A., Cruise, K., Munoz, L. C., Aucion, K. J., \& Morris, A. S. (2008b) Assessing Callous-Unemotional Traits in Adolescent Offenders. International Journal of Law and Psychiayry, 31, 241252. http://dx.doi.org/10.1016/j.ijlp.2008.04.002

Klein, M. H., \& Benjamin, L. S. (1996). The Wisconsin Personality Disorders Inventory-IV. Madison, WI: University of Wisconsin. (unpublished test, Available from Dr. M. H. Klein, Department of Psychiatry, Wisconsin Psychiatric Institute and Clinic, 6001 Research Park Blvd., Madison, WI 53719-1179)

Klein, M. H., Benjamin, L. S., Rosenfeld, R., Treece, C., Hsted, J., \& Greist, J. H. (1993). The Wisconsin Personality Disorders Inventory. I: Development, Reliability, and Validity. Journal of Personality Disorders, Supplement, 18-33.

Kosson, D. S., Blackburn, R., Byrnes, K. A., Park, S., Logan, C., \& Donnelly, J. P. (2008). Assessing Interpersonal Aspects of Schizoid Personality Disorder: Preliminary Validation Studies. Journal of Personality Assessment, 90, 185-196. http://dx.doi.org/10.1080/00223890701845427

Krueger, R. F., Derringer, J., Markon, K. E., Watson, D., \& Skodol, A. E. (2012). Initial Construction of a Maladaptive Personality Trait Model and Inventory for DSM-5. Psychological Medicine, 42, 1879-1890. http://dx.doi.org/10.1017/S0033291711002674

Kwapil, T. R., Barrantes-Vidal, N., \& Silvia, P. J. (2008). The Dimensional Structure of the Wisconsin Schizotypy Scales: Factor Identification and Construct Validity. Schizophrenia Bulletin, 34, 444-457. http://dx.doi.org/10.1093/schbul/sbm098

Langbehn, D. R., Pfohl, B. M., Reynolds, S., Clark, L. A., Battaglia, M., Bellodi, L., Cadoret, R., Grove, W., Pilkonis, P., \& Links, P. (1999). The Iowa Personality Disorder Screen: Development and Preliminary Validation of a Brief Screening Interview. Journal of Personality Disorders, 1, 75-89. http://dx.doi.org/10.1521/pedi.1999.13.1.75

Lenzenweger, M. F. (1999). Stability and Change in Personality Disorder Features: The Longitudinal Study of Personality Disorders. Archives of General Psychiatry, 11, 1009-1015. http://dx.doi.org/10.1001/archpsyc.56.11.1009

Lenzenweger, M. F., Bennett, M. E., \& Lilenfeld, L. R. (1997). The Referential Thinking Scale as a Measure of Schizotypy: Scale Development and Initial Construct Validation. Psychological Assessment, 9, 452-463. http://dx.doi.org/10.1037/1040-3590.9.4.452

Lenzenweger, M. F., Loranger, A. W., Korfine, L., \& Neff, C. (1997). Detecting Personality Disorders in a Nonclinical Population. Application of a 2-Stage Procedure for Case Identification. Archives of General Psychiatry, 4, 345-351. http://dx.doi.org/10.1001/archpsyc.1997.01830160073010

Levenson, M. R., Kiehl, K. A., \& Fitzpatrick, C. M. (1995). Assessing Psychopathic Attributes in a Noninstitutionalised Population. Journal of Personality and Social Psychology, 68, 151-158. http://dx.doi.org/10.1037/0022-3514.68.1.151

Lewin, T. J., Slade, T., Andrews, G., Carr, V. J., \& Hornabrook, C. W. (2005). Assessing Personality Disorders in a National Mental Health Survey. Social Psychiatry and Psychiatric Epidemiology, 2, 87-98. http://dx.doi.org/10.1007/s00127-005-0878-1

Lilienfeld, S. O., \& Widows, M. R. (2005). Psychopathic Personality Inventory-Revised. Lutz, FL: Psychological Assessment Resources, Inc.

Lobbestael, J., Leurgans, M., \& Arntz, A. (2011). Inter-Rater Reliability of the Structured Clinical Interview for DSM-IV Axis I Disorders (SCID I) and Axis II Disorders (SCID II). Clinical Psychology and Psychotherapy, 18, 75-79. http://dx.doi.org/10.1002/cpp.693

Loranger, A. W. (1994). Omnibus Personality Inventory Manual. White Plains, NY: New York Hospital—Cornell Medical Center, Westchester Division.

Loranger, A. W. (1999). International Personality Disorder Examination (IPDE). Odessa, FL: Psychological Assessment Resources.

Loranger, A. W. (2002). OMNI Personality Inventory and OMNI-IV Personality Disorder Inventory Manual. Odessa, FL: Psychological Assessment Resources. 
Lorant, T. A., Henderson, L., \& Zimbardo, P. G. (2000). Comorbidity in Chronic Shyness. Depression and Anxiety, 12, 232237. http://dx.doi.org/10.1002/1520-6394(2000)12:4<232::AID-DA7>3.0.CO;2-\#

Lynam, D. R., Gaughan, E. T., Miller, J. D., Miller, D. J., Mullins-Sweatt, S., \& Widiger, T. A. (2011). Assessing the Basic Traits Associated with Psychopathy: Development and Validation of the Elemental Psychopathy Assessment. Psychological Assessment, 23, 108-124. http://dx.doi.org/10.1037/a0021146

Lynam, D. R., Loehr, A., Miller, J. D., \& Widiger, T. A. (2012). A Five-Factor Measure of Avoidant Personality: The FFAvA. Journal of Personality Assessment, 94, 466-474. http://dx.doi.org/10.1080/00223891.2012.677886

Mahieu, C., Hare, R. D., Jones, D. N., Babiak, P., \& Neumann, C. S. (2012). Factor Structure of the B-Scan 360: A Measure of Corporate Psychopathy. Psychological Assessment. Avance Online Publication. http://dx.doi.org/10.1037/a0029262

Margolis, H. D., \& Thomas, V. A. (1980). The Measurement of Narcissism in Adolescents with and without Behavioral and Emotional Disabilities. Unpublished Master's Thesis, San Diego, CA: United States International University.

Mason, O., \& Claridge, G. (1999). Individual Differences in Schizotypy and Reduced Asymmetry Using the Chimeric Faces Task. Cognitive Neuropsychiatry, 4, 289-301. http://dx.doi.org/10.1080/135468099395846

Mason, O., Claridge, G., \& Jackson, M. (1995). New Scales for the Assessment of Schizotypy. Personality and Individual Differences, 18, 7-13. http://dx.doi.org/10.1016/0191-8869(94)00132-C

McDermut, W., \& Zimmerman, M. (2008). Personality Disorders, Personality Traits, and Defense Mechanisms. In A. J. Rush, M. B. First, \& D. Blacker (Eds.), Handbook of Psychiatric Measures (pp. 687-729). Washington, DC: American Psychiatric Association.

Melley, A. H., Oltmanns, T. F., \& Turkheimer, E. (2002). The Schedule for Adaptive and Nonadaptive Personality (SNAP): Temporal Stability and Predictive Validity of the Diagnostic Scales. Assessment, 9, 181-187. http://dx.doi.org/10.1177/10791102009002009

Miller, J. D., Bagby, R. M., Pilkonis, P. A., Reynolds, S. K., \& Lynam, D. R. (2005). A Simplified Technique for Scoring DSM-IV Personality Disorders with the Five-Factor Model. Assessment, 12, 404-415.

Miller, J. D., Few, L. R., \& Widiger, T. A. (2012). Assessment of Personality Disorders and Related Traits: Bridging DSM-IV-TR and DSM-5. In T. A. Widiger (Ed.), Oxford Handbook of Personality Disorder (pp. 108-140). New York: Oxford University Press.

Miller, J. D., Maples, J., Few, L. R., Morse, J. Q., Yaggi, K. E., \& Pilkonis, P. A. (2010). Using Clinician-Rated Five-Factor Model Data to Score the DSM-IV Personality Disorders. Journal of Personality Assessment, 92, 296-305. http://dx.doi.org/10.1080/00223891.2010.481984

Miller, L. (2008). From Difficult to Disturbed. New York: Amacom.

Millon, T. (1983). Millon Clinical Multiaxial Inventory. Minneapolis, MN: Interpretive Scoring Systems.

Millon, T. (1987). Manual for Millon Clinical Multiaxial Inventory II (MCMI-II). Minneapolis, MN: National Computer Systems.

Millon, T., Davis, R., \& Millon, C. (1997). MCMI-III Manual (2nd ed.). Minneapolis, MN: National Computer Systems.

Millon, T., Millon, C., Davis, R., \& Grossman, S. (2009). MCMI-III Manual (4th ed.). Minneapolis, MN: Pearson Education, Inc.

Moran, P., Leese, M., Lee, T., Walters, P., Thornicroft, G., \& Mann, A. (2003). Standardised Assessment of PersonalityAbbreviated Scale (SAPAS): Preliminary Validation of a Brief Screen for Personality Disorder. British Journal of Psychiatry, 183, 228-232. http://dx.doi.org/10.1192/bjp.183.3.228

Morey, L. C. (1991). Personality Assessment Inventory-Professional Manual. Florida, USA: Psychological Assessment Resources, Inc.

Morey, L. C., Hopwood, C. J., Gunderson, J. G., Skodol, A. E., Shea, M. T., Yen, S., \& McGlashan, T. H. (2007). Comparison of Alternative Models for Personality Disorders. Psychological Medicine, 37, 983-994. http://dx.doi.org/10.1017/S0033291706009482

Morey, L. C., Hopwood, C. J., Markowitz, J. C., Gunderson, J. G., Grilo, C. M., McGlashan, T. H., Skodol, A. E. et al. (2012). Comparison of Alternative Models for Personality Disorders, II: 6-, 8- and 10-Year Follow-Up. Psychological Medicine, 42, 1705-1713. http://dx.doi.org/10.1017/S0033291711002601

Morey, L. C., Waugh, M. H., \& Blashfield, R. K. (1985). MMPI Scales for DSM-III Personality Disorders: Their Derivation and Correlations. Journal of Personality Assessment, 49, 245-251. http://dx.doi.org/10.1207/s15327752jpa4903_5

Mullins, L. S., \& Kopelman, R. E. (1988). Toward an Assessment of the Construct Validity of Four Measures of Narcissism. Journal of Personality Assessment, 52, 610-625. http://dx.doi.org/10.1207/s15327752jpa5204_2

Mullins-Sweat, S. N., Edmundson, M., Sauer-Zavala, S., Lynam, D. R., Miller, J. D., \& Widiger, T. A. (2012). Five-Factor Measure of Borderline Personality Traits. Journal of Personality Assessment, 1-13. 
Murray, H. (1938). Explorations in Personality. New York: Oxford University Press.

Okada, M., \& Oltmanns, T. F. (2009). Comparison of Three Self-Report Measures of Personality Pathology. Journal of Psychopathology and Behavioral Assessment, 31, 358-367. http://dx.doi.org/10.1007/s10862-009-9130-8

Oldham, J., \& Morris, L. (1991). Personality Self-Portrait. New York: Bantam.

Olssøn, I., Sørebø, Ø., \& Dahl, A. A. (2011). A Cross-Sectional Testing of The Iowa Personality Disorder Screen in a Psychiatric Outpatient Setting. BMC Psychiatry, 11, 105-112. http://dx.doi.org/10.1186/1471-244X-11-105

Pfohl, B., Blum, N., \& Zimmerman, M. (1997). Structured Interview for DSM-IV Personality. Washington, DC: American Psychiatric Press.

Pfohl, B., Blum, N., St. John, D., McCormick, B., Allen, J., \& Black, D. W. (2009). Reliability and Validity of the Borderline Evaluation of Severity Over Time (BEST): A Self-Rated Scale to Measure Severity and Change in Persons with Borderline Personality Disorder. Journal of Personality Disorders, 23, 281-293. http://dx.doi.org/10.1521/pedi.2009.23.3.281

Pfohl, B., Stangl, D., \& Zimmerman, M. (1983). The Structured Interview for DSM III Personality Disorders (2nd ed.). Iowa City, IA: University of Iowa Hospitals and Clinics.

Phillips, K. A. et al. (2010). Should an Obsessive-Compulsive Spectrum Grouping of Disorders be Included in DSM-V? Depression and Anxiety, 27, 528-555. http://dx.doi.org/10.1002/da.20705

Pickersgill, M. (2010). From Psyche to Soma? Changing Accounts of Antisocial Personality Disorder in the American Journal of Psychiatry. History of Psychiatry, 21, 294-311. http://dx.doi.org/10.1177/0957154X09102800

Pincus, A. L., Ansell, E. B., Pimentel, C. A., Cain, N. M., Wright, A. G. C., \& Levy, K. N. (2009). Initial Construction and Validation of the Pathological Narcissism Inventory. Psychological Assessment, 21, 365-379. http://dx.doi.org/10.1037/a0016530

Poreh, A. M., Rawlings, D., Claridge, G., Freeman, J. L., Faulkner, C., Shelton, C. (2006). The BPQ: A Scale for the Assessment of Borderline Personality Based on DSM-IV Criteria. Journal of Personality Disorders, 20, 247-260. http://dx.doi.org/10.1521/pedi.2006.20.3.247

Priftera, A., \& Ryan, J. J. (1984). Validity of the Narcissistic Personality Inventory (NPI) in a Psychiatric Sample. Journal of Clinical Psychology, 40, 140-142.

http://dx.doi.org/10.1002/1097-4679(198401)40:1<140::AID-JCLP2270400127>3.0.CO;2-E

Raine, A. (1991). The SPQ: A Scale for the Assessment of Schizotypal Personality Based on DSM-III-R Criteria. Schizophrenia Bulletin, 17, 555-564. http://dx.doi.org/10.1093/schbul/17.4.555

Raine, A., \& Benishay, D. (1995). The SPQ-B: A Brief Screening Instrument for Schizotypal Personality Disorder. Journal of Personality Disorders, 9, 346-355. http://dx.doi.org/10.1521/pedi.1995.9.4.346

Ramanaiah, N. V., \& Sharpe, J. P. (1998). Structure of the Coolidge Axis II Inventory Personality Disorder Scales from the Five-Factor Perspective. Psychological Reports, 83, 947-952. http://dx.doi.org/10.2466/pr0.1998.83.3.947

Raskin, R. \& Terry, H. (1988). A Principal-Component Analysis of the Narcissistic Personality Inventory and Further Evidence of Its Construct Validity. Journal of Personality and Social Psychology, 54, 890-902. http://dx.doi.org/10.1037/0022-3514.54.5.890

Raskin, R., \& Hall, C. (1979). A Narcissistic Personality Inventory. Psychological Reports, 45, 590. http://dx.doi.org/10.2466/pr0.1979.45.2.590

Raskin, R., \& Hall, C. S. (1981). The Narcissistic Personality Inventory: Alternative Form Reliability and Further Evidence of Construct Validity. Journal of Personality Assessment, 45, 159-162. http://dx.doi.org/10.1207/s15327752jpa4502_10

Retzlaff, P. (1996). MCMI-III Diagnostic Validity: Bad Test or Bad Validity. Journal of Personality Assessment, 66, 431437. http://dx.doi.org/10.1207/s15327752jpa6602 19

Richman, J. A., \& Flaherty, J. A. (1990). Gender differences in narcissistic styles. In Plakun, E. M. (Ed.), New perspective on narcissism (pp. 73-100). Washing, DC: American Psychiatric Press.

Rogers, R. (2001). Handbook of Diagnostic and Structural Interviewing. New York: Guilford.

Rogers, R. (2003). Standardizing DSM-IV Diagnoses: The Clinical Applications of Structured Interviews. Journal of Personality Assessment, 81, 220-225. http://dx.doi.org/10.1207/S15327752JPA8103 04

Rolland, J. P., \& Pichot, P. (2007). Manuel de l'inventaire de Tendances Dysfonctionelles TD-12. Paris: ECPA.

Salekin, R. T., Rogers, R., \& Sewell, K. W. (2006). A Review and Meta-Analysis of the Psychopathy Checklist and Psychopathy Checklist-Revised: Predictive Validity of Dangerousness. Clinical Psychology: Science and Practice, 3, $203-215$. http://dx.doi.org/10.1111/j.1468-2850.1996.tb00071.x

Samuel, D. B., \& Widiger, T. A. (2008). A Meta-Analytic Review of the Relationships between the Five-Factor Model and DSM-IV-TR Personality Disorders: A Facet Level Analysis. Clinical Psychology Review, 28, 1326-1342.

http://dx.doi.org/10.1016/j.cpr.2008.07.002 
Samuel, D. B., Riddell, A. D. B., Lynam, D. R., Miller, J. D., \& Widiger, T. A. (2012). A Five-Factor Measure of ObsessiveCompulsive Personality Traits. Journal of Personality Assessment, 94, 456-465.

Schuler, C. E., Snibbe, J. R., \& Buckwalter, J. G. (1994). Validity of the MMPI Personality Disorder Scales (MMPI-PD). Journal of Clinical Psychology, 50, 220-227.

http://dx.doi.org/10.1002/1097-4679(199403)50:2<220::AID-JCLP2270500211>3.0.CO;2-J

Segal, D. L., \& Coolidge, F. L. (2007). Structured and Semi-Structured Interviews for Differential Diagnosis: Issues and Application. In M. Hersen, S. M. Turner, \& D. C. Beidel (Eds.), Adult Psychopathology and Diagnosis (5th ed., pp. 72-103). New York: John Wiley \& Sons.

Sellen, J. L., Oaksford, M., \& Gray, N. S. (2005). Schizotypy and Conditioning Reasoning. Schizophrenia Bulletin, 31, 105116. http://dx.doi.org/10.1093/schbul/sbi012

Silberman, C. S., Roth, L., Segal, D. L., \& Burns, W. J. (1997). Relationship between the Millon Clinical Multiaxial Inventory-II and Coolidge Axis II Inventory in Chronically Mentally Ill Older Adults: A Pilot Study. Journal of Clinical Psychology, 53, 559-566. http://dx.doi.org/10.1002/(SICI)1097-4679(199710)53:6<559::AID-JCLP4>3.0.CO;2-F

Simms, L. J. \& Clark, L. A. (2006). The Schedule for Nonadaptive and Adaptive Personality (SNAP): A Dimensional Measure of Traits Relevant to Personality and Personality Pathology. In S. Strack (Ed.), Differentiating Normal and Abnormal Personality Pathology (pp. 431-450). New York: Springer.

Skodol, A. E., Oldham, J. M., Rosnick, L., Kellman, H. D., \& Hyler, S. E. (1991). Diagnosis of DSM-III-R Personality Disorders: A Comparison of Two Structured interviews. International Journal of Methods in Psychiatric Research, 1, 13-26.

Slade, T., Peters, L., Schneiden, V., \& Andrews, G. (2006). The International Personality Disorder Examination Questionnaire (IPDEQ): Preliminary Data on Its Utility as a Screener for Anxious Personality Disorder. International Journal of Methods in Psychiatric Research, 7, 84-88. http://dx.doi.org/10.1002/mpr.37

Slavin-Mulford, J., Sinclair, S. J., Stein, M., Malone, J., Bello, I., \& Blais, M. A. (2012). External Validity of the Personality Assessment Inventory (PAI) in a Clinical Sample. Journal of Personality Assessment, 94, 593-600. http://dx.doi.org/10.1080/00223891.2012.681817

Smith, T. L., Klein, M. H., Alonson, C., Salazar-Fraile, J., Felipe-Castano, E., Moreno, C. L., Acosta, S. R., Rios, L. I., \& Marti-Sanjuan, V. (2011). The Spanish Version of the Wisconsin personality Disorders Inventory-IV (WISPI-IV): Tests of Validity and Reliability. Journal of Personality Disorders, 25, 813-833. http://dx.doi.org/10.1521/pedi.2011.25.6.813

Startup, M. (1999). Schizotypy, dissociative experiences and childhood abuse: relationships among self-report measures. British Journal of Clinical Psychology, 38, 333-344. http://dx.doi.org/10.1348/014466599162908

Tomiatti, M., Gore, W. L., Lynam, D. R., Miller, J. D., \& Widiger, T. A. (2012). A Five-Factor Measure of Histrionic Personality Traits. In A. Columbus (Ed.), Advances in Psychology Research (Vol. 87, pp. 113-138). Hauppauge, NY: Nova Science Publishers.

Trull, T. J., \& Amdur, M. (2001). Diagnostic Efficiency of the Iowa Personality Disorder Screen Items in a Nonclinical Sample. Journal of Personality Disorders, 15, 351-357. http://dx.doi.org/10.1521/pedi.15.4.351.19184

Trull, T. J., Goodwin, A. H., Schopp, L. H., Hillenbrand, T. L., \& Schuster, T. (1993). Psychometric Properties of a Cognitive Measure of Personality Disorders. Journal of Personality Assessment, 61, 536-546. http://dx.doi.org/10.1207/s15327752jpa6103_10

Tyrer, P. (2000). Personality Assessment Schedule: PAS-I (ICD-10 Version). In P. Tyrer (Ed.), Personality Disorders: Diagnosis, Management and Course (pp. 160-180). London: Arnold.

Tyrer, P., Morgan, J., \& Cicchetti, D. (2004). The Dependent Personality Questionnaire (DPQ): A Screening Instrument for Dependent Personality. International Journal of Social Psychiatry, 50, 10-17. http://dx.doi.org/10.1177/0020764004038754

Uehara, T., Sakado, K., \& Sato, T. (1997). Test—Retest Reliability of the Personality Diagnostic Questionnaire: Revised. Psychiatry and Clinical Neurosciences, 51, 369-372. http://dx.doi.org/10.1111/j.1440-1819.1997.tb02601.x

Useda, J. D. (2002). The Construct Validity of the Paranoid Personality Disorder Features Questionnaire (PPDFQ): A Dimensional Assessment of Paranoid Personality Disorder. Dissertation Abstracts International, 62, 9B.

Uzieblo, K., Verschuere, B., Van den Bussche, E., \& Crombez, G. (2010). The Validity of the Psychopathic Personality Inventory—Revised in a Community Sample. Assessment, 17, 334-346. http://dx.doi.org/10.1177/1073191109356544

Vitale, J. E., Smith, S. S., Brinkley, C. A., \& Newman, J. P. (2002). Reliability and Construct Validity of the Psychopathy Checklist-Revised in Female Offenders. Criminal Justice and Behavior, 29, 202-231. http://dx.doi.org/10.1177/0093854802029002005

Watson, D. C., \& Sinha, B. K. (1996). A Normative Study of the Coolidge Axis II Inventory. Journal of Clinical Psychology, 52, 631-637. http://dx.doi.org/10.1002/(SICI)1097-4679(199611)52:6<631::AID-JCLP5>3.0.CO;2-N

Watson, D., \& Sinha, B. (2007). A Normative Study of the Coolidge Axis-II Inventory, Short Form. Psychology and Psy- 
chotherapy: Theory, Research, and Practice, 80, 437-441. http://dx.doi.org/10.1348/147608306X154825

Westen, D., \& Shedler, J. (2007). Personality Diagnosis with the Shedler-Westen Assessment Procedure (SWAP): Integrating Clinical and Statistical Measurement and Prediction. Journal of Abnormal Psychology, 116, 810-822. http://dx.doi.org/10.1037/0021-843X.116.4.810

Widiger, T. A., \& Clark, L. A. (2009). Toward DSM-V and the Classification of Psychopathology. Psychological Bulletin, 126, 946-963.

Widiger, T. A., \& Costa Jr., P. T. (2013). Personality Disorders and the Five-Factor Model of Personality. Washington, DC: American Psychological Association. http://dx.doi.org/10.1037/13939-000

Widiger, T. A., Livesley, W. J., \& Clark, L. A. (2009). An Integrative Dimensional Classification of Personality Disorder. Psychological Assessment, 21, 243-255. http://dx.doi.org/10.1037/a0016606

Widiger, T. A., Mangine, S., Corbitt, E. M., Ellis, C. G., \& Thomas, G. V. (1995). Personality Disorder Interview-IV. A Semi Structured Interview for the Assessment of Personality Disorders. Professional Manual. Odessa, FL: Psychological Assessment Resources.

Widiger, T. A., \& Boyd, S. (2009). Personality Disorders Assessment Instruments. In J. N. Butcher (Ed.), Oxford Handbook of Personality Assessment (pp. 336-363). New York: Oxford University Press.

Widiger, T. A., Costa, P. T., \& Samuel, D. (2006). Assessment of Maladaptive Personality Traits. In S. Strack, \& M. Lorr (Eds.), Differentiating Normal and Abnormal Personality (2nd ed., pp. 311-355). New York: Springer.

Wille, B., De Fruyt, F., \& De Clercq, B. (2013). Expanding and Reconceptualizing Aberrant Personality at Work: Validity of Five-Factor Model Aberrant Personality Tendencies to Predict Career Outcomes. Personnel Psychology, 66, 173-223. http://dx.doi.org/10.1111/peps.12016

Zanarini, M. C., Frankenburg, F. R., Hennen, J., \& Silk, K. R. (2003). The Longitudinal Course of Borderline Psychopathology: 6-Year Prospective Follow-Up of the Phenomenology of Borderline Personality Disorder. American Journal of Psychiatry, 2, 274-283. http://dx.doi.org/10.1176/appi.ajp.160.2.274

Zanarini, M. C., Frankenburg, F. R., Sickel, A. E., \& Yong, L. (1996). The Diagnostic Interview for DSM-IV Personality Disorders (DIPD-IV). Belmont, MA: McLean Hospital.

Zanarini, M. C., Frankenburg, F. R., Vujanovic, A. A. (2002). Inter-Rater and Test-Retest Reliability of the Revised Diagnostic Interview for Borderlines. Journal of Personality Disorders, 16, 270-276. http://dx.doi.org/10.1521/pedi.16.3.270.22538

Zanarini, M. C., Gunderson, J. G., Frankenburg, F. R., \& Chauncey, D. L. (1989). The Revised Diagnostic Interview for Borderlines: Discriminating BPD from Other Axis II Disorders. Journal of Personality Disorders, 3, 10-18. http://dx.doi.org/10.1521/pedi.1989.3.1.10

Zanarini, M. C., Vujanovic, A. A., Parachini, E. A., Boulanger, J. L., Frankenburg, F. R., \& Hennen, J. (2003). Zanarini Rating Scale for Borderline Personality Disorder (ZAN-BPD): A Continuous Measure of DSM-IV Borderline Psychopathology. Journal of Personality Disorders, 17, 233-242. http://dx.doi.org/10.1521/pedi.17.3.233.22147

Zimmerman, M. (2003). What Should the Standard of Care for Psychiatric Diagnostic Evaluations Be? Journal of Nervous and Mental Disease, 191, 281-286. http://dx.doi.org/10.1097/01.NMD.0000066149.40946.FA 
Scientific Research Publishing (SCIRP) is one of the largest Open Access journal publishers. It is currently publishing more than 200 open access, online, peer-reviewed journals covering a wide range of academic disciplines. SCIRP serves the worldwide academic communities and contributes to the progress and application of science with its publication.

Other selected journals from SCIRP are listed as below. Submit your manuscript to us via either submit@scirp.org or Online Submission Portal.
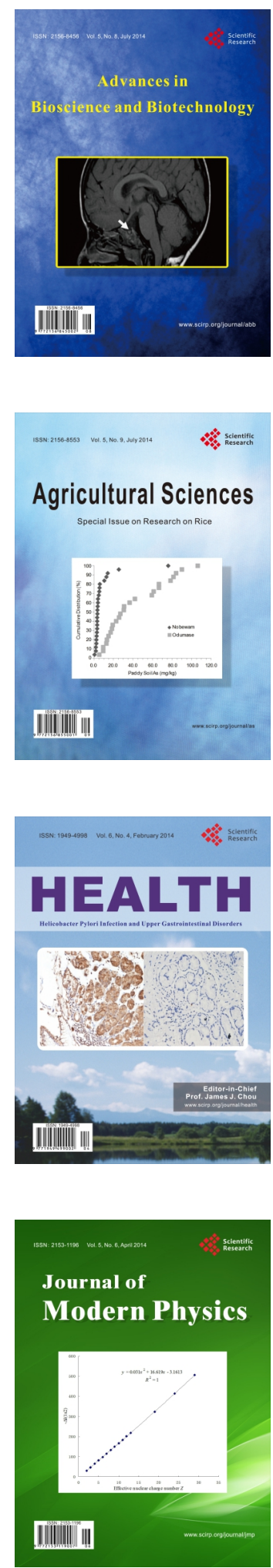
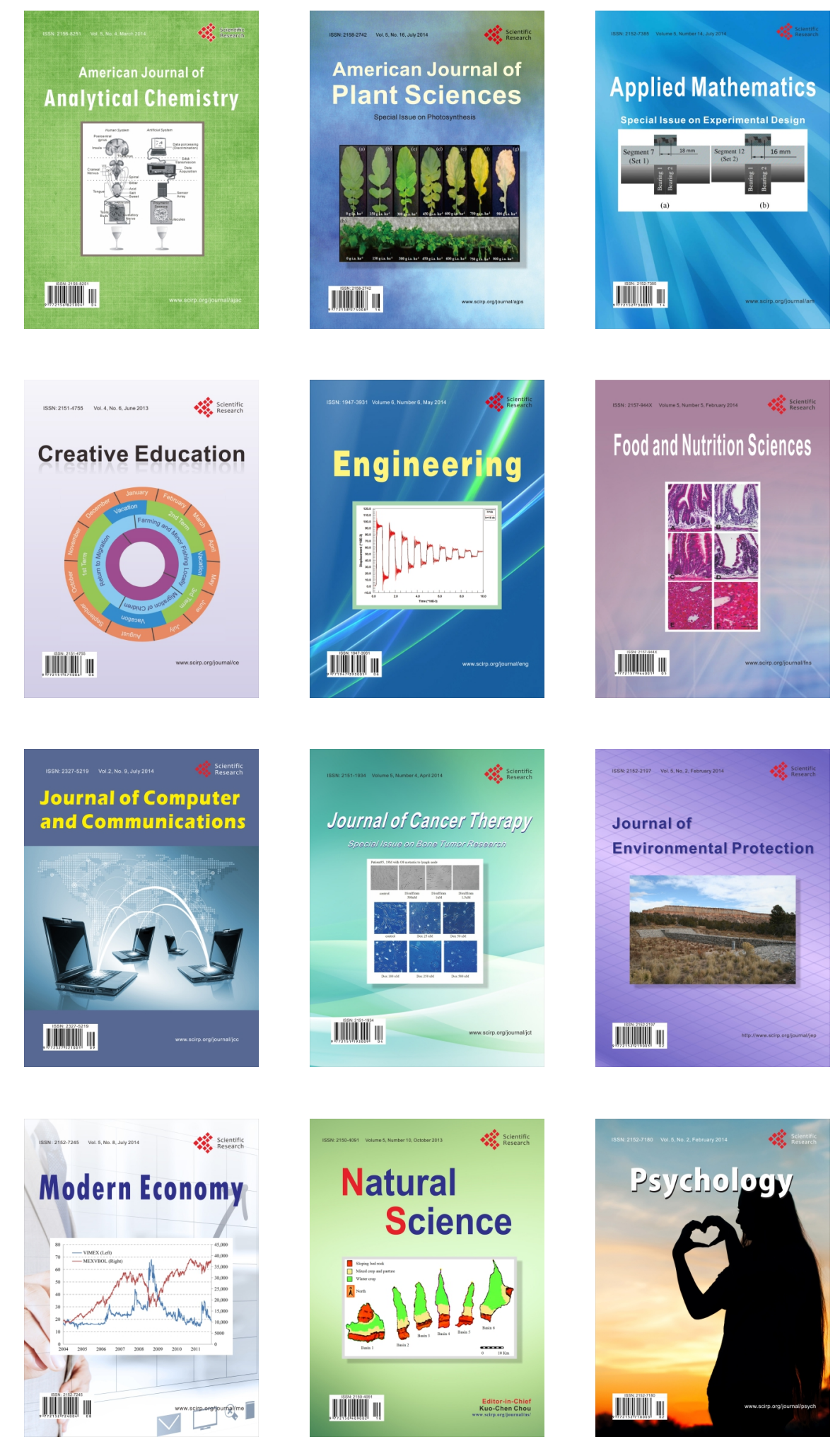